(2) Open Access Full Text Article

REVIEW

\title{
Hypervalent iodine reagents for heterocycle synthesis and functionalization
}

This article was published in the following Dove Press journal:

Reports in Organic Chemistry

9 August 2016

Number of times this article has been viewed

\author{
Jiyun Sun' \\ Daisy Zhang-Negrerie ${ }^{2}$ \\ Yunfei Du' \\ Kang Zhao' \\ 'Tianjin Key Laboratory for Modern \\ Drug Delivery and High-Efficiency, \\ School of Pharmaceutical Science and \\ Technology, Tianjin University, Tianjin, \\ ${ }^{2}$ Concordia International School \\ Shanghai, Shanghai, People's Republic \\ of China
}

\begin{abstract}
Hypervalent iodine reagents have been vastly applied in many significant oxidative reactions. This surging interest in iodine reagents is mainly due to the very useful oxidizing properties, combined with their benign environmental character and commercial availability. In this review, we focus on the representative transformations that used the common hypervalent iodine reagents as oxidants in heterocycle synthesis and functionalizations, based on the type of the hypervalent iodine reagents.
\end{abstract}

Keywords: hypervalent iodine reagent, heterocycle synthesis, heterocycle functionalization, oxidative reaction

\section{Introduction}

The 1990s witnessed rapid development of hypervalent iodine chemistry. The intense interest is mainly due to the remarkable oxidizing properties of hypervalent iodine reagents and their attractive features such as easy to handle, low toxicity, availability of supply, and environmental benignity. ${ }^{1-20}$ Two of their most important synthetic applications are in the constructions of heterocyclic skeletons and functionalization of heterocycles, such as three- to seven-membered rings and spiro compounds, under metal-free reaction conditions. Some representative transformations have been shown in Figure 1. In this review, we summarize, with representative examples, the reactions involving various hypervalent iodine (III) and (IV) reagents used as oxidants for the syntheses and functionalization of heterocyclic compounds. The organization of the presentation is based on the type of the hypervalent iodine reagents.

\section{Hypervalent iodine (III) reagents}

The common classification of hypervalent iodine (III) reagents is according to the type of ligands attached to the iodine atom, as shown in Figure 2. ${ }^{10,16}$ These broadly applied hypervalent iodine (III) reagents, namely, iodosylarenes 1, (dichloroiodo) arenes $\mathbf{2} \mathbf{a}$ and (difluoroiodo)arenes $\mathbf{2 b}$, [bis(acyloxy)iodo] arenes $\mathbf{3}$, [hydroxy(tosyloxy) iodo]benzene 4 (Koser's reagent), iodonium salts $\mathbf{5}$, iodonium ylides and iodonium imides, and the benziodoxole-based hypervalent iodine reagents 6 and 7 (Togni's reagents), have been found to be powerful and effective oxidants for the synthesis of heterocycles and for facilitating functionalization of heterocyclic compounds via atom transfer reactions.
Correspondence: Yunfei Du; Kang Zhao Tianjin Key Laboratory for Modern Drug Delivery and High-Efficiency, School of Pharmaceutical Science and Technology, Tianjin University, Tianjin 300072,

People's Republic of China

Tel +8622 27404031

Email kangzhao@tju.edu.cn 


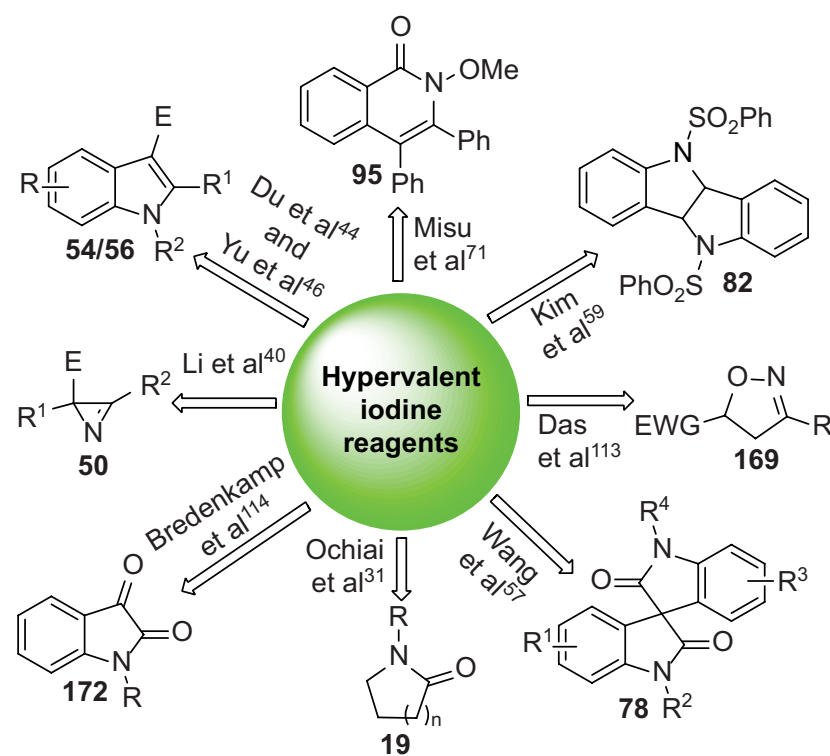

Figure I Representative reactions involving hypervalent iodine reagents.

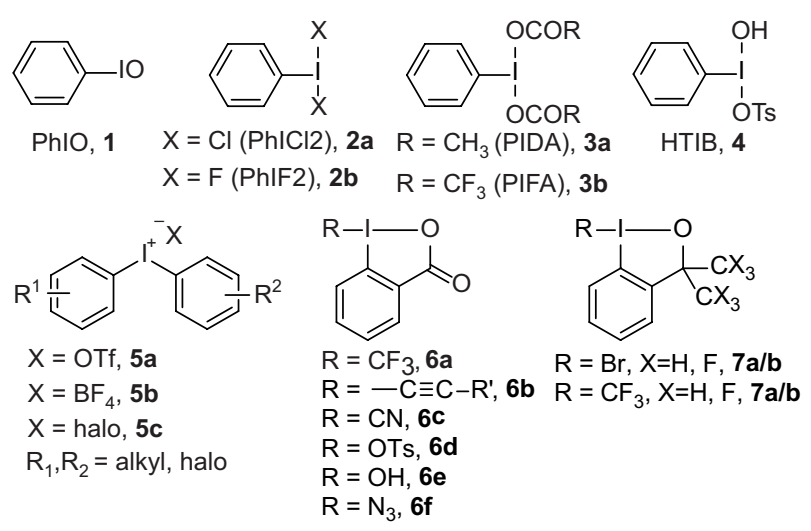

Figure 2 Representative hypervalent iodine (III) reagents.

Abbreviations: PhIO, iodosobenzene; PIDA, phenyliodine diacetate; PIFA, phenyliodine bis(trifluoroacetate); HTIB, [hydroxy(tosyloxy)iodo]benzene.

\section{lodosylarenes}

An important synthetic application of iodosobenzene (PhIO) is promoting oxidative annulation during the construction of heterocyclic framework. For example, Ueno et $\mathrm{al}^{21}$ reported a direct preparation of heteroaromatic compounds of imidazoles 9a, thiaozles 9b, and imidazo[1,2- $a$ ]pyridines $\mathbf{1 0}$ through reactions of alcohol substrates 8 with $\mathrm{PhIO}$ catalyzed by $p$-toluenesulfonic acid monohydrate and followed by further reactions with thioamide, benzamidine, and 2-aminopyridine, respectively, under basic conditions (Figure 3).

In 2010, Fan et $\mathrm{al}^{22}$ described a PhIO-mediated synthesis of the three-membered $N$-benzoyl aziridines $\mathbf{1 2}$ and the five-membered oxazolines 13 through an intramolecular oxidative cyclization of substrates $\mathbf{1 1}$ in the presence of catalytic amount of tetra-butylammonium iodide (Figure 4A-a). Similar conditions were applied to the synthesis of

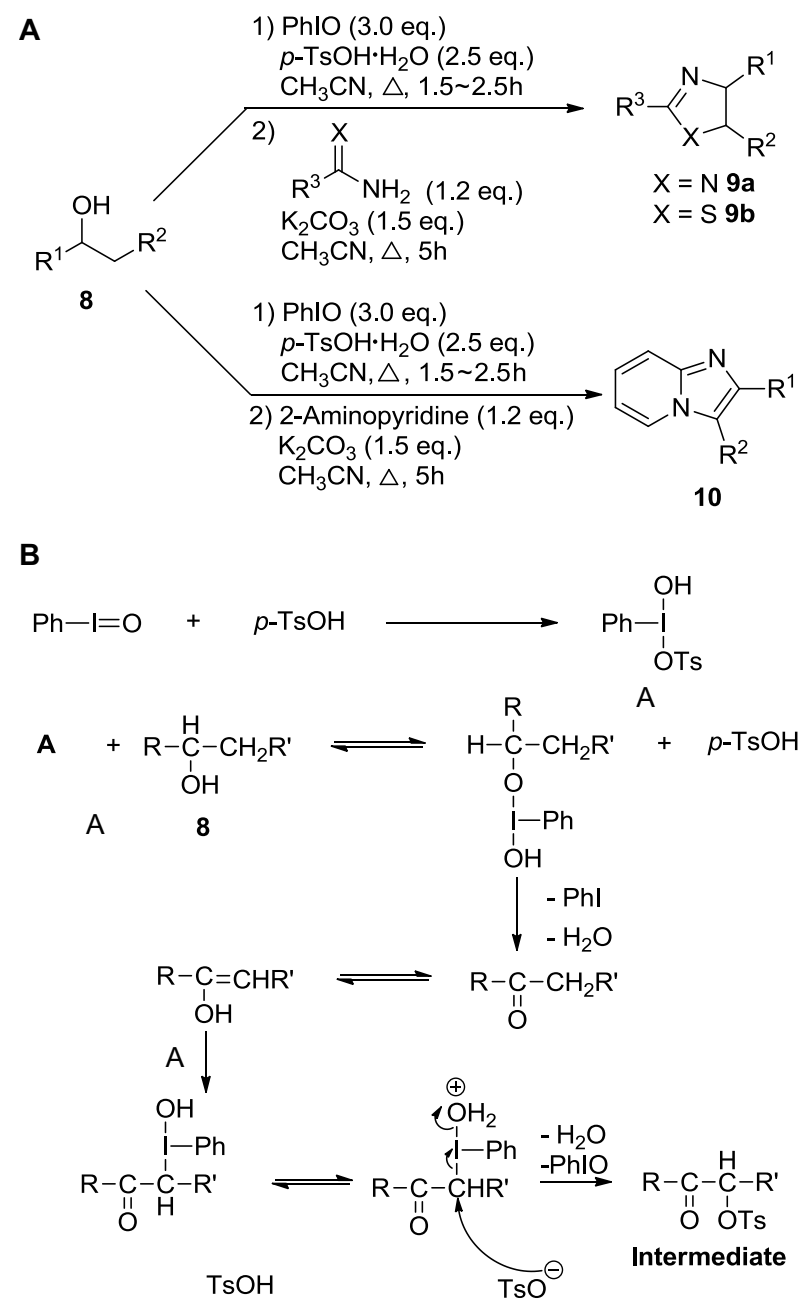

Figure 3 (A) PhlO-mediated construction of thiaozles, imidazoles, and imidazo[I,2-a]pyridines. (B) Proposed mechanism of the oxidation reaction in step I. Abbreviations: $\mathrm{PhlO}$, iodosobenzene; eq., equivalent; $\mathrm{h}$, hours.

the four-membered oxetanes $\mathbf{1 5}$ and azetidines $\mathbf{1 7}$ from substrates 14 and 16, respectively (Figure 4A-b and -c). ${ }^{23,24}$ The proposed mechanism has been shown in Figure 4B.

In addition, $\mathrm{PhIO}$ can also be used as an efficient oxidant for the functionalization of heterocycles. For example, fiveor six-membered lactams 19 could be obtained in moderate yields through the oxidation of cyclic amines $\mathbf{1 8}$ with $\mathrm{PhIO}$ using $\mathrm{H}_{2} \mathrm{O}$ as solvent (Figure 5). ${ }^{25}$

Moriarty et $\mathrm{al}^{26}$ reported the oxidation of trimethylsilyl ketene acetals of lactones $\mathbf{2 0}$ in methanol, mediated by $\mathrm{PhIO}$, to afford the corresponding $\alpha$-methoxylated carbonyl compounds 21 in good yields (Figure 6). They also found that reaction of dihydropyran 22 with $\mathrm{PhIO}$ in $\mathrm{H}_{2} \mathrm{O}$ could afford tetrahydro-2-furaldehyde $\mathbf{2 3}$ via carbocationic ring contraction (Figure 7). Under the same conditions, cyclohexene and styrene were converted into the corresponding aldehyde products through rearrangement oxidations. $^{27}$ 
a)

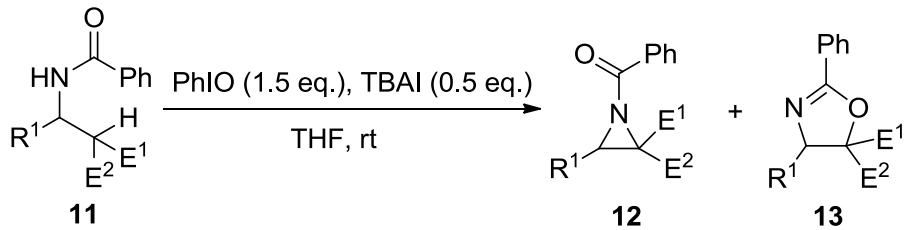

b)

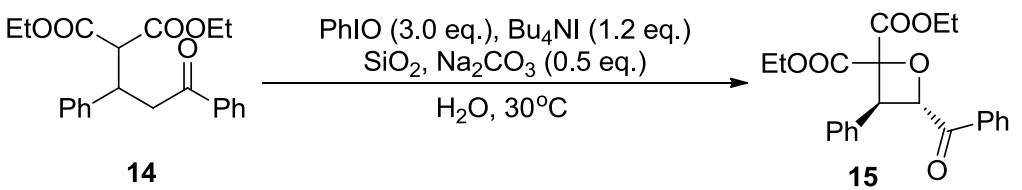

c)
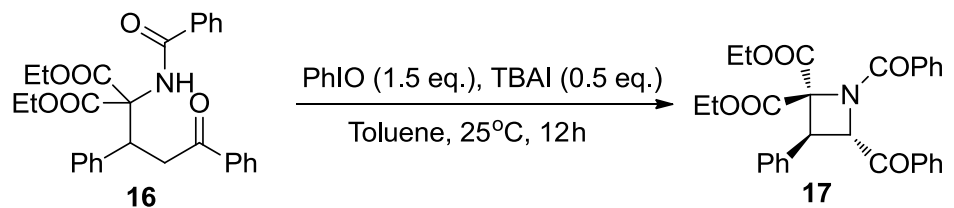

B

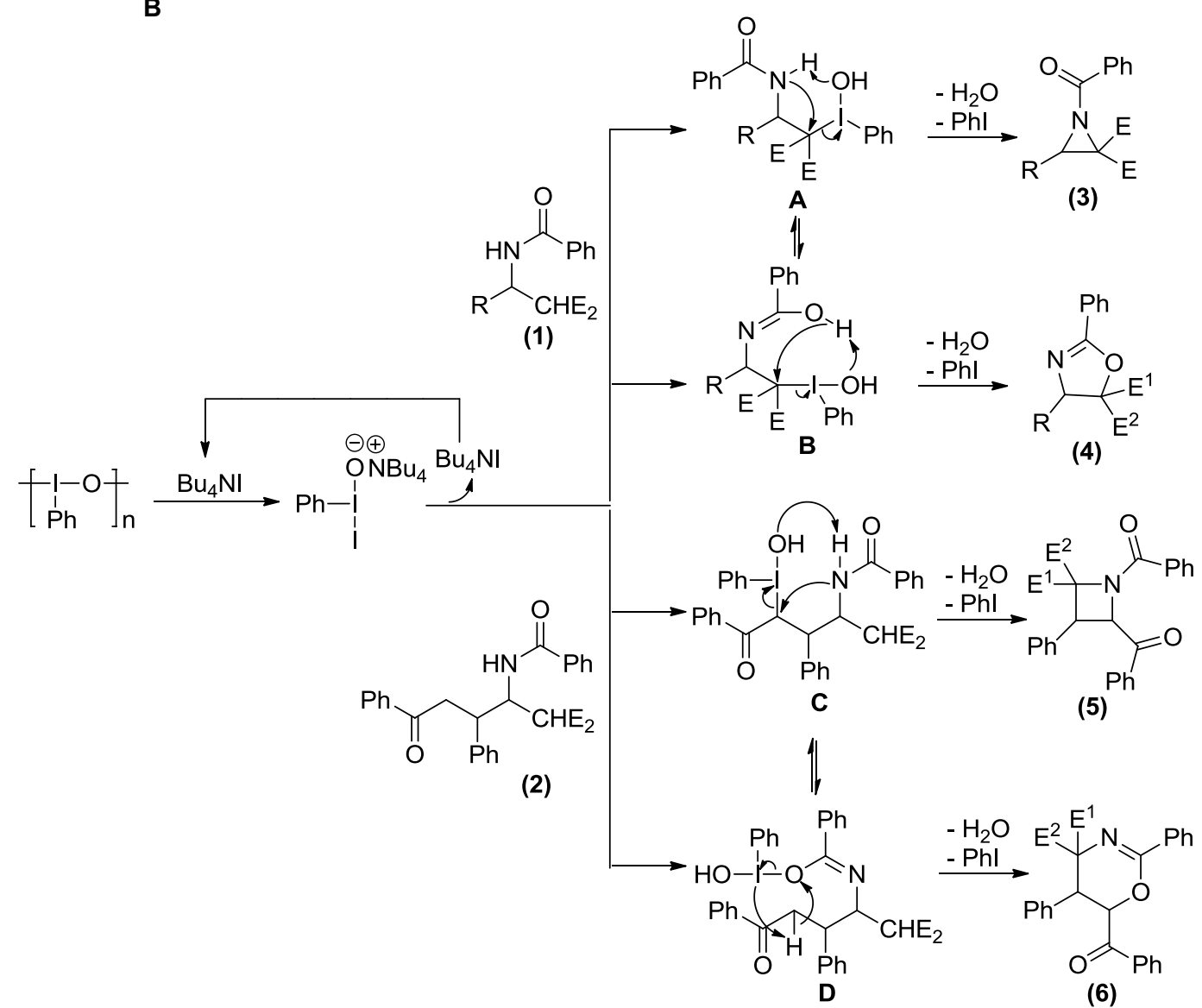

Figure 4 (A) (a) PhlO-mediated synthesis of three-membered ring 12 and five-membered ring I3. (b) PhlO-mediated synthesis of oxetane I5. (c) PhIO-mediated synthesis of azetidine 17 (B) Proposed mechanism of (a) and (c)

Abbreviations: $\mathrm{PhIO}$, iodosobenzene; eq., equivalent; TBAI, tetra-butylammonium iodide; THF, tetrahydrofuran; rt, room temperature; h, hours.

In the presence of $\mathrm{PhIO}$ and $\mathrm{I}_{2}, \mathrm{~N}$ - or $\mathrm{O}$-centered radicals could be generated, respectively, from amides or alcohols. ${ }^{28-30}$ In 2000, Francisco et al reported the synthesis of homochiral 7-oxa-2-azabicyclo[2.2.1] heptane ring system 28 from specifically protected phosphoramidate derivatives of carbohydrates
24 under the conditions mentioned earlier. Mechanistic studies demonstrated a reaction path involving a hemolytic fragmentation of a hypothetical iodoamide intermediate $\mathbf{2 6}$ (Figure 8). ${ }^{30}$

It is worth noting that the applications of $\mathrm{PhIO}$ can be significantly restricted in nonpolar solvents due to low 
solubility. Therefore, the majority of the known reactions occurs in polar solvents and are catalyzed by a Lewis acid or a transition metal catalyst, with only a few cases reported to be in a nonpolar solvent or without the involvement of a catalyst. One of the rare examples is the formation of lactams 30 in $\mathrm{CHCl}_{3}$ from the cyclic amino acids 29 via initial imine formation followed by oxidative decarboxylation (Figure 9). ${ }^{31}$

\section{(Difluoroiodo)arenes}

As fluorinating reagents, (difluoroiodo)arenes $\left(\mathrm{ArIF}_{2}\right)$ have found many synthetic applications for the syntheses of biologically and pharmaceutically interesting F-containing heterocyclic compounds. ${ }^{32,33}$ In 1991, Caddick et al ${ }^{32}$ reported the reaction of 1-(arylthio)glycosides 31 with TolIF $_{2}$, which afforded various 1-fluoroglycosides 32 in moderate-to-good yields (Figure 10).

Upon treating the iodoaldyl substituted four-, five-, and six-membered cyclic ethers 33-35 with TolIF ${ }_{2}$, the five-, six-, and seven-membered cyclic ethers 36-38 were stereoselectively synthesized in moderate-to-good yields (Figure 11). ${ }^{34}$

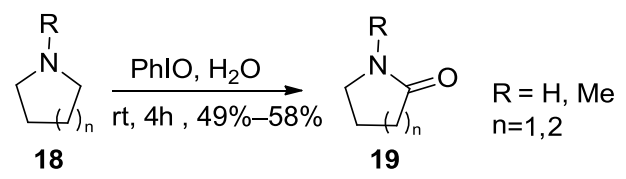

Figure 5 PhlO-mediated functionalization of cyclic amines.

Abbreviations: $\mathrm{PhlO}$, iodosobenzene; rt, room temperature; h, hours.

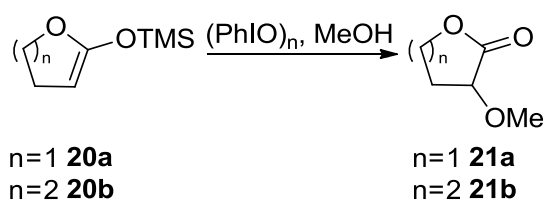

Figure 6 PhlO-mediated oxidation affording $\alpha$-methoxylated carbonyl compounds. Abbreviation: $\mathrm{PhlO}$, iodosobenzene.

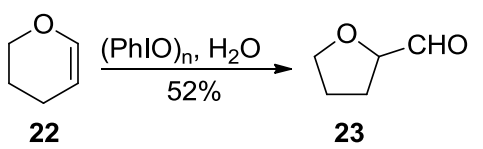

Figure $7 \mathrm{PhlO}$-mediated oxidation of dihydropyran.

Abbreviation: $\mathrm{PhlO}$, iodosobenzene.

\section{Dichloroiodoarene}

(Dichloroiodo)arenes $\left(\mathrm{ArICl}_{2}\right)$ have been used as chlorinating reagents to carry out modification of various heterocyclic compounds. For example, reaction of $N$-protected pyrrolidine 39 with 4-nitrobenzeneiododichloride afforded $\alpha$-hydroxy$\beta, \beta$-dichloropyrrolidine $\mathbf{4 0}$ as the main product via a complicated ionic mechanism involving a $\mathrm{C}\left(\mathrm{sp}^{3}\right)-\mathrm{H}$ bond activation process (Figure 12). This oxidation gave an $\alpha, \beta, \beta$-oxidation pattern relative to the nitrogen of the heterocycle. ${ }^{35}$

An effective system consisting of a combination of $\mathrm{PhICl}_{2}$ and $\mathrm{Pb}(\mathrm{SCN})_{2}$ was developed by Prakash et al ${ }^{36}$ for convenient thiocyanation of various enol silyl ethers 41 (Figure 13).

Recently, Hepples et a ${ }^{37}$ reported a Lewis base-catalyzed chlorination method for the diazocarbonyl compound 43a and isatin-3-hydrazone $\mathbf{4 3 b}$ by using $\mathrm{PhICl}_{2}$, both of which led to the same product 44 (Figure 14).

The common feature of these reactions is the transfer of the two chlorine ligands from $\mathrm{PhICl}_{2}$ in a germinal fashion rather than vicinal. ${ }^{37,38}$

In 2014 , He et al ${ }^{39}$ reported a method for the direct synthesis of oxazolidin-2-ones $\mathbf{4 6}$ and imidazolidin-2-ones $\mathbf{4 8}$ from 1,3-diols 45 and 3-amino alcohols 47 using combined $\mathrm{PhICl}_{2}$ and $\mathrm{NaN}_{3}$ (Figure 15).

\section{[Bis(acyloxy)iodo]arenes}

[Bis(acyloxy)iodo]arenes ( $\left.\mathrm{ArI}(\mathrm{OCOR})_{2}\right)$, notably the easily prepared and commercially available phenyliodine diacetate (PIDA) and phenyliodine bis(trifluoroacetate) (PIFA), have been widely used as oxidizing reagents in various syntheses of heterocycles. In this review, the applications of PIDA and PIFA are presented based on the type of heterocycles obtained.

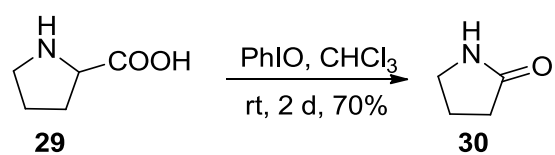

Figure 9 PhlO-mediated conversion of proline into 2-pyrrolidone in nonpolar solvent.

Abbreviations: PhlO, iodosobenzene, rt, room temperature; $d$, days.<smiles>[R]NCC1O[C@H](C)[C@@H]([R9])[C@H]([R6])[C@H]1O[R20]</smiles>

$\mathrm{R}=$ alkyl, $\mathrm{R}^{\prime}=\mathrm{P}(\mathrm{O})(\mathrm{OPh})_{2}$

Figure 8 Synthesis of the homochiral 7-oxa-2-azabicyclo[2.2.1] heptane ring system.

Abbreviations: $\mathrm{PhIO}$, iodosobenzene; IHA, intramolecular hydrogen abstraction reaction. 


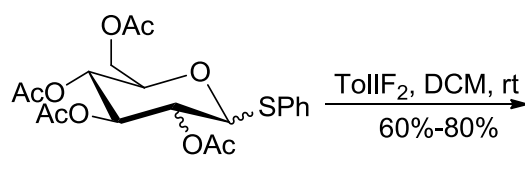

31

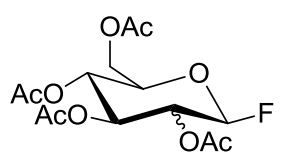

$32 a$

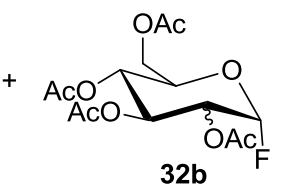

Figure 10 Synthesis of various I-fluoroglycosides with TollF 2 .

Abbreviations: $r$, room temperature; DCM, dichloromethane.

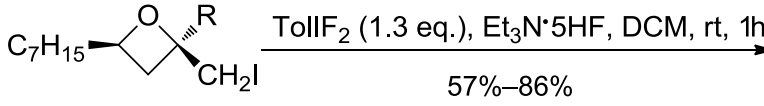

$33 \mathrm{R}=\mathrm{H}, \mathrm{Me}$

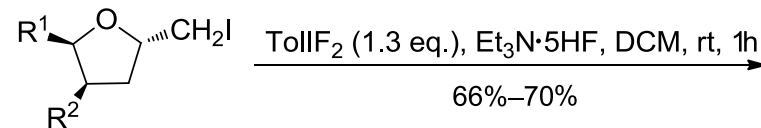

$34 \quad \mathrm{R}^{1}=\mathrm{C}_{5} \mathrm{H}_{11}$ or $\mathrm{Ph}, \mathrm{R}^{2}=\mathrm{H}$

$\mathrm{R}^{1}=\mathrm{H}, \mathrm{R}^{2}=\mathrm{Ph}$

${ }^{\mathrm{Pr}}{ }_{\mathrm{CH}_{2} \mathrm{I}}^{\mathrm{Me}}$

TollF $_{2}$ (1.3 eq.), Et ${ }_{3} N \cdot 5 H F$, DCM, rt, 1h

35

$66 \%-70 \%$ ed by TollF

Figure I I Ring-expansion reactions in

Abbreviations: eq., equivalent; rt, room temperature; h, hour; DCM, dichloromethane.

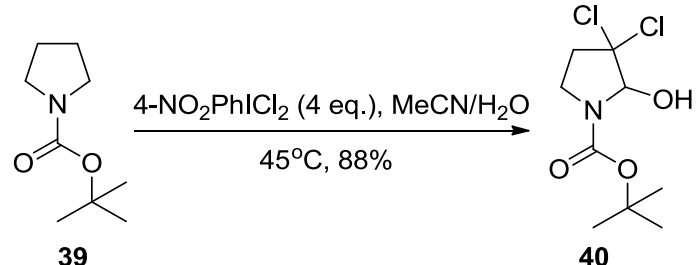

39

40
Figure 12 Synthesis of $\alpha$-hydroxy- $\beta, \beta$-dichloropyrrolidine with $4-\mathrm{NO}_{2} \mathrm{PhICl}_{2}$. Abbreviation: eq., equivalent.

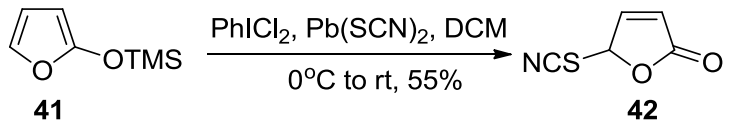

Figure $13 \mathrm{PhICl}_{2} / \mathrm{Pb}(\mathrm{SCN})_{2}$-mediated thiocyanation of enol silyl ethers leading to lactone 42.

Abbreviations: rt, room temperature; DCM, dichloromethane.

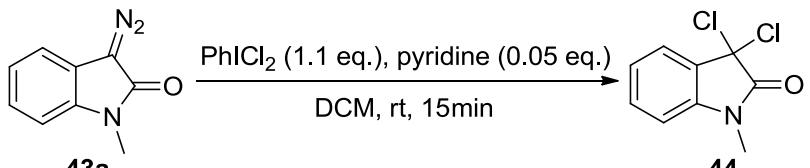<smiles>CN1C(=O)/C(=N\N)c2ccccc21</smiles>

$43 b$

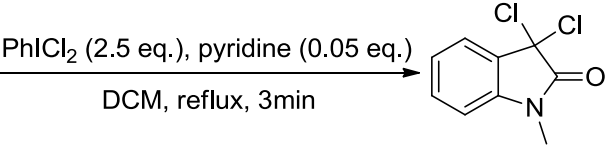

44
Figure 14 Lewis base-catalyzed chlorination facilitated by $\mathrm{PhICl}_{2}$.

Abbreviations: eq., equivalent; rt, room temperature; min, minutes; DCM, dichloromethane.
A
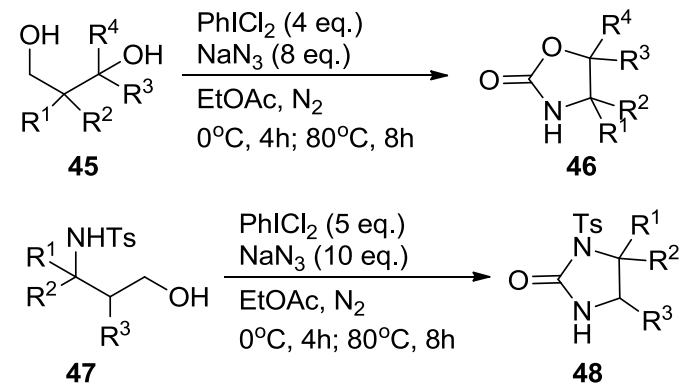

B

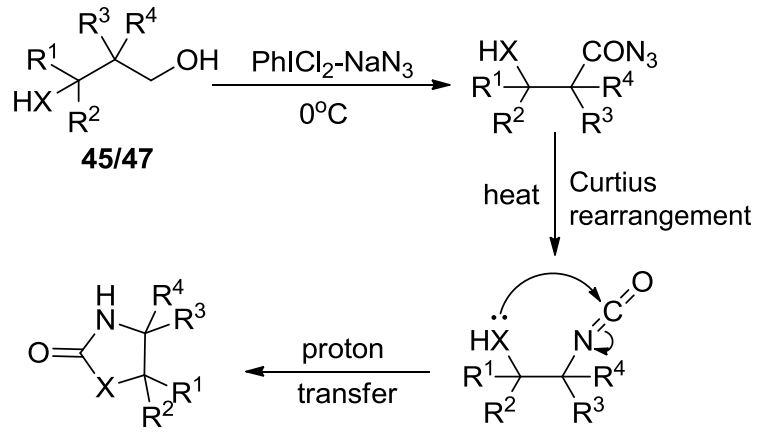

$46 / 48$

Figure I5 (A) Direct synthesis of oxazolidin-2-ones and imidazolidin-2-ones using $\mathrm{PhICl}_{2}$ and $\mathrm{NaN}_{3}$. (B) Proposed mechanism.

Abbreviations: eq., equivalent; $h$, hours. 


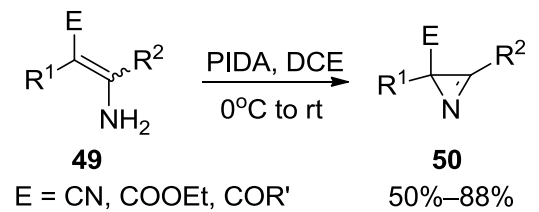

Figure 16 PIDA-mediated synthesis of $2 \mathrm{H}$-azirine derivatives from enamines. Abbreviations: PIDA, phenyliodine diacetate; $\mathrm{rt}$, room temperature; DCE, I,2-dichloroethane.

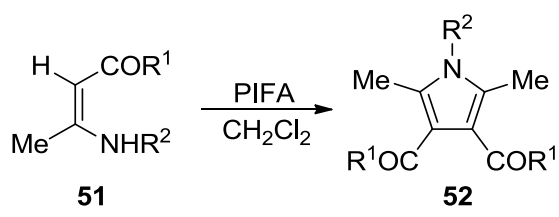

Figure 17 PIFA-mediated synthesis of polysubstituted pyrroles $\mathbf{5 2}$. Abbreviation: PIFA, phenyliodine bis(trifluoroacetate).

A<smiles>[R]N/C([R])=C(/F)c1cc[R1]cc1</smiles>

$\mathrm{E}=\mathrm{CN}, \mathrm{COOEt}$

$\mathrm{R}=\mathrm{H}, \mathrm{OMe}, \mathrm{CF}_{3}$, halogens

$\mathrm{R}^{1}=$ alkyl; $\mathrm{R}^{2}=$ aryl, alkyl

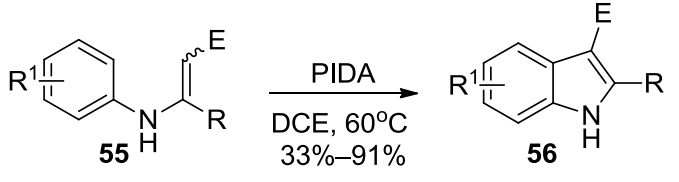

$\mathrm{E}=\mathrm{CN}, \mathrm{NO}_{2}, \mathrm{COOMe}, \mathrm{COPh}$

$\mathrm{R}=$ aryl, alkyl, COOEt

$\mathrm{R}^{1}=\mathrm{H}, \mathrm{Me}, \mathrm{OMe}, \mathrm{Br}, \mathrm{F}$

Figure I8 (A) I (III)-mediated synthesis of indoles from enamines 53. (B) I (III)mediated synthesis of indoles from enamines 55 .

Abbreviations: PIDA, phenyliodine diacetate; PIFA, phenyliodine bis(trifluoroacetate); rt, room temperature; DCM, dichloromethane; DCE, I,2-dichloroethane.

\section{Three-membered heterocyclic products}

In 2009, our group reported the synthesis of the smallest unsaturated $\mathrm{N}$-containing heterocycle, namely, $2 \mathrm{H}$-azirine 50, via PIDA-mediated intramolecular oxidative azirination of the substituted enamine derivatives $\mathbf{4 9}$ under mild conditions (Figure 16) ${ }^{40} \mathrm{~A}$ similar strategy was later applied to the one-pot synthesis of isoxazoles from enaminones. ${ }^{41}$

\section{Five-membered heterocyclic compounds Pyrrole}

Mediated by PIFA, the synthesis of polysubstituted pyrroles 52 was achieved via a tandem dimerization/cyclocondensation of enaminones 51 (Figure 17). ${ }^{42}$ Asymmetrical polysubstituted pyrroles were obtained from enamine esters or ketones mediated by PIDA in the presence of $\mathrm{BF}_{3} \cdot \mathrm{Et}_{2} \mathrm{O} \cdot{ }^{43}$
A

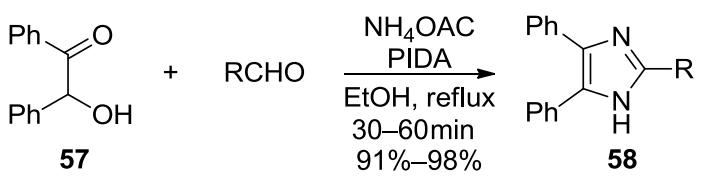

B

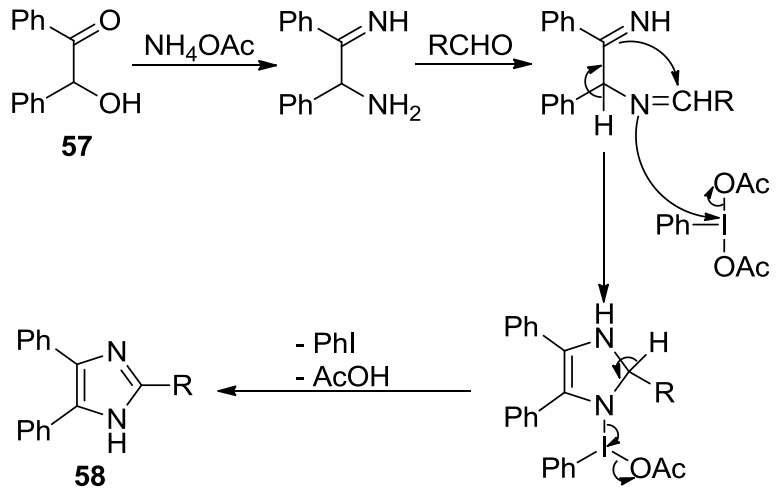

Figure 19 (A) PIDA-mediated synthesis of imidazoles via condensation of $\alpha$-hydroxy ketones with aldehydes and $\mathrm{NH}_{4} \mathrm{OAc}$. (B) Proposed mechanism. Abbreviations: PIDA, phenyliodine diacetate; min, minutes.

Indole

In 2006, the syntheses of $N$-arylated and $N$-alkylated indoles 54 from enamine derivatives 53 were realized through a PIFA-mediated intramolecular oxidative $\mathrm{C}\left(\mathrm{sp}^{2}\right)-\mathrm{N}$ bond formation (Figure 18A). ${ }^{44}$ The same strategy was also applied to the synthesis of carbazolones via PIFA-mediated intramolecular cyclization of 2-aryl enaminones..$^{45}$ In 2009, a variety of functionalized indoles 56 were synthesized from $N$-aryl enamines 55 via PIDAmediated oxidative $\mathrm{C}\left(\mathrm{sp}^{2}\right)-\mathrm{C}\left(\mathrm{sp}^{2}\right)$ involving no transition metals (Figure 18B) ${ }^{46}$

\section{Azole}

In 2007, Das et a ${ }^{47}$ reported the condensation of $\alpha$-hydroxy ketones 57 with aldehydes and ammonium acetate by using PIDA as the sole oxidant. The reaction furnished the cyclized imidazole product 58 through an oxidative $\mathrm{C}\left(\mathrm{sp}^{2}\right)-\mathrm{N}$ bond formation (Figure 19). Various 2-arylbenzimidazoles and benzimidazoles were later synthesized adopting the same methodology. ${ }^{48}$

In 1996, Kotali ${ }^{49}$ realized the synthesis of aminoindazole derivatives 60 from the $o$-aminoaryl ketone acylhydrazones 59 via PIDA-mediated $\mathrm{N}-\mathrm{N}$ bond formation (Figure 20).

In 2012, intramolecular oxidative $\mathrm{C}-\mathrm{O}$ coupling of $N$-(4-alkoxy-phenyl) and $N$-(4-acetamido-phenyl) benzamides was found to afford the benzoxazole products in high yields under metal-free conditions by using PIFA as an oxidant and TMSOTf as a catalyst (Figure 21). ${ }^{50}$ 
Upon treating $\beta$-monosubstituted enamines 63 with PIFA, an intermolecular cross-coupling occurred and was succeeded by condensation to provide the 4,5-disubstituted 2-(trifluoromethyl)oxazoles 64 (Figure 22).$^{51}$ In this approach, the trifluoromethyl moiety in one of the PIFA ligands was incorporated into the final products at the $\mathrm{C} 2$ position.

In 2010, Saito et a ${ }^{52}$ reported the oxidative cycloisomerization of propargylamide derivatives $\mathbf{6 5}$, mediated by PIDA in $\mathrm{AcOH}$ or AcOH-HFIP and affording the corresponding 2,5-disubstituted oxazoles 66 (Figure 23).

Treating anthranilamides $67 \mathbf{a}$ or salicylamides $67 \mathbf{b}$ with PIDA in the presence of potassium hydroxide, the 2-benzimidazolones 68a and 2-benzoxazolones $68 \mathrm{~b}$ were,

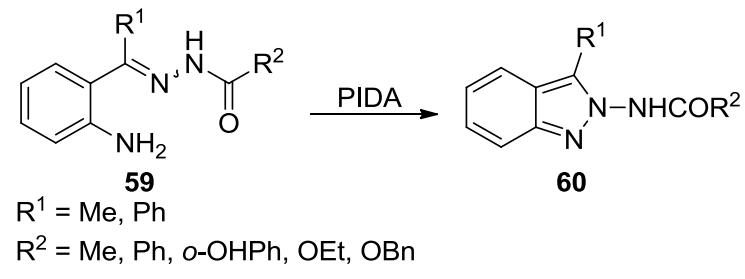

Figure 20 PIDA-mediated synthesis of aminoindazole derivatives. Abbreviation: PIDA, phenyliodine diacetate.

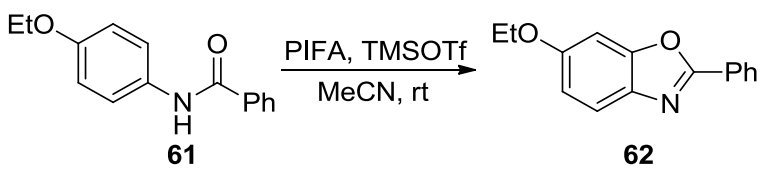

Figure 2I PIFA/TMSOTf-mediated synthesis of benzoxazole derivatives. Abbreviations: PIFA, phenyliodine bis(trifluoroacetate); rt, room temperature; TMSOTf, trimethylsilyl trifluoromethanesulfonate. respectively, obtained in good yields (Figure 24). The postulated mechanistic pathway suggested an initial Hofmanntype rearrangement followed by a sequential intramolecular cyclization of the intermediate isocyanate. ${ }^{53}$

In 2008, PIFA-mediated intramolecular cyclization of the thiobenzamides 69 resulting in the benzothiazoles 70 via reactive intermediates of aryl radical cations was described (Figure 25A). ${ }^{54}$ Later on, Kumar et $\mathrm{al}^{55}$ applied the polymersupported PIDA to construct the benzothiazoles $\mathbf{7 3}$ from the corresponding $o$-amino benzenethiol components $\mathbf{7 1}$ and aldehydes 72 (Figure 25B).

\section{Lactone}

In 2007, Dohi et a ${ }^{56}$ developed a direct construction of the biologically important aryl lactone $\mathbf{7 6}$ from carboxylic acid 74 using combined PIDA and $\mathrm{KBr}$ (Figure 26). The aryl group in the substrate was understood to be indispensable due to the benzyl radical intermediate $\mathbf{7 5}$ as suggested by the mechanism. The aryl lactone product $\mathbf{7 6}$ was achieved via hydrogen abstraction and then cyclization.

\section{Spiro heterocycles and bisindolines}

In 2012, Wang et al ${ }^{57}$ reported a PIFA-mediated synthesis of spirooxindoles $\mathbf{7 8}$ from anilide derivatives $\mathbf{7 7}$ bearing an appropriate $\alpha$-arylaminocarbonyl group (Figure 27). These processes feature a metal-free oxidative $\mathrm{C}\left(\mathrm{sp}^{2}\right)-\mathrm{C}\left(\mathrm{sp}^{3}\right)$ bond formation, followed by oxidative spirocyclization.

A

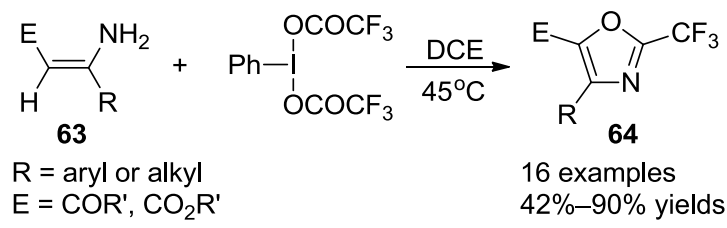

B
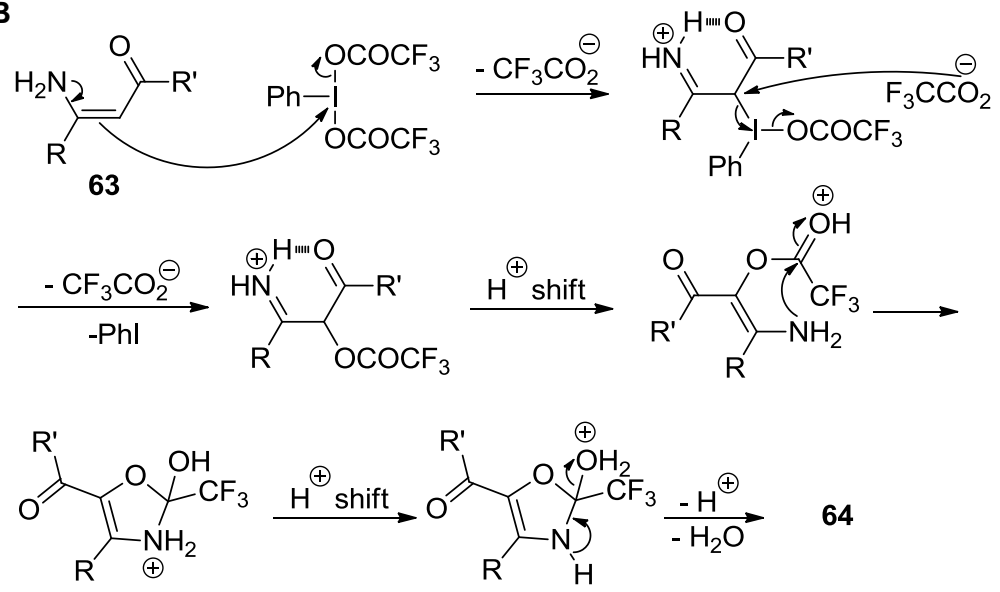

64

Figure 22 (A) PIFA-mediated synthesis of 2-trifluoromethyl oxazole derivatives. (B) Proposed mechanism.

Abbreviation: PIFA, phenyliodine bis(trifluoroacetate); DCE, I,2-dichloroethane. 


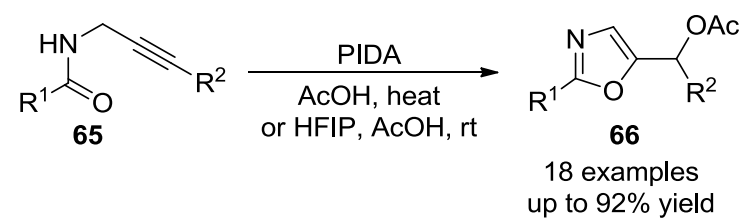

Figure 23 PIDA-mediated synthesis of 2,5-disubstituted oxazoles in $\mathrm{AcOH}$ or AcOH-HFIP.

Abbreviations: PIDA, phenyliodine diacetate; rt, room temperature.

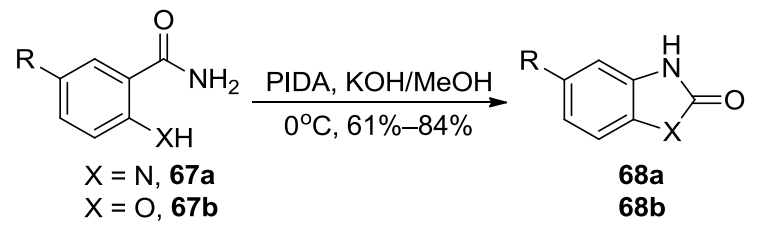

Figure 24 PIDA/KOH-mediated synthesis of 2-benzimidazolones and 2-benzoxazolones.

Abbreviation: PIDA, phenyliodine diacetate.
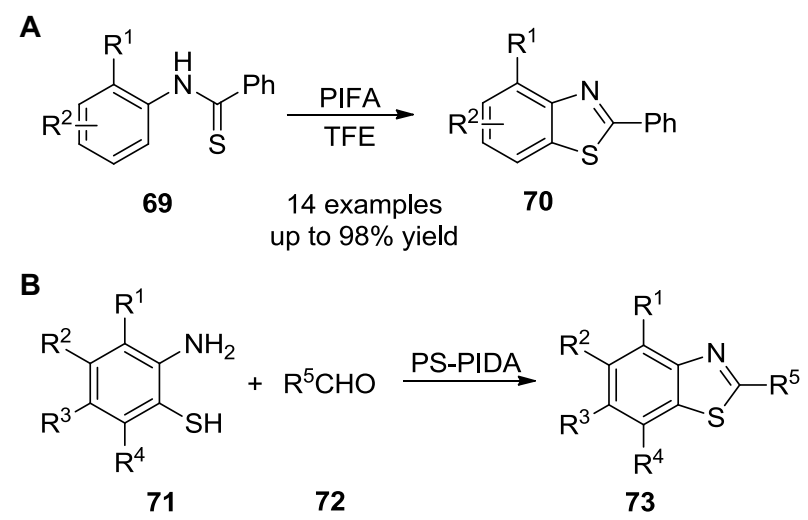

Figure 25 (A) PIFA-mediated intramolecular synthesis of benzothiazoles. (B) PIDAmediated intermolecular synthesis of benzothiazoles.

Abbreviations: PIDA, phenyliodine diacetate; PIFA, phenyliodine bis(trifluoroacetate); PS, polymer-supported.

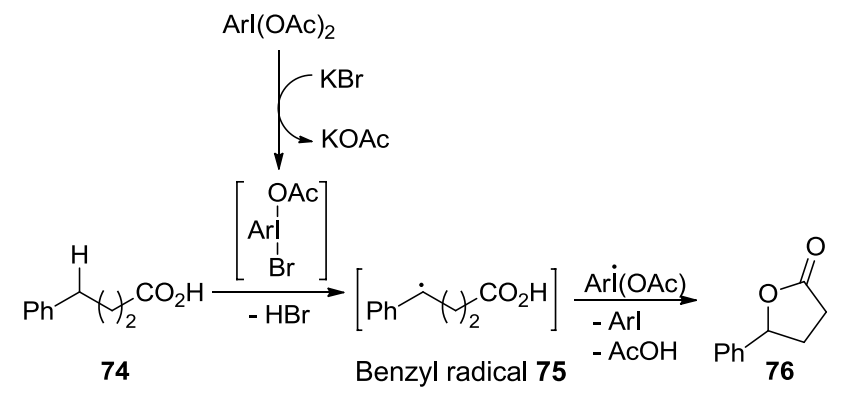

Figure $26 \mathrm{PIDA} / \mathrm{KBr}$-mediated synthesis of aryl lactones. Abbreviation: PIDA, phenyliodine diacetate.

Recently, Zhang et a ${ }^{58}$ reported a PIFA-mediated cascade annulation of internal alkyne 79, affording the spiro heterocycle 80 (Figure 28). This process encompasses not only two sequential $\mathrm{C}-\mathrm{N} / \mathrm{C}-\mathrm{O}$ bond formations but also the insertion of a carbonyl oxygen, all in one pot.

In 2014, Kim et al ${ }^{59}$ realized a cascade intramolecular oxidative diamination of olefins $\mathbf{8 1}$ by using PIDA as an oxidant and a halide as an additive, leading to the synthesis of a variety of bisindolines 82 (Figure 29).

\section{Six- and seven-membered heterocycles}

A PIFA-mediated oxidative $\mathrm{C}\left(\mathrm{sp}^{2}\right)-\mathrm{C}\left(\mathrm{sp}^{2}\right)$ bond formation between two aryl rings was reported by Kita et al. ${ }^{60}$ Later, this oxidative coupling strategy was widely applied to the conversion of various biaryl substrates tethered by a relatively labile linker attached to the heterocycles, such as a silaketale, sulfide, sulfoxide, sulfone, or dibenzylether. ${ }^{61-63}$ For example, Moreno et $\mathrm{al}^{64}$ described an efficient synthesis of benzo[c] phenanthridine 84 and phenanthridinone $\mathbf{8 6}$ from properly substituted benzylnaphthylamine 83 and naphthylbenzamide 85, respectively, through a PIFA-mediated intramolecular oxidative $\mathrm{C}-\mathrm{C}$ bond formation between the two electron-rich phenyl rings (Figure 30).

Liu et $a{ }^{65}$ reported the syntheses of a variety of 3-arylquinolin-2-one compounds $\mathbf{8 8}$ from the $N$-methyl- $N$ phenylcinnamamides 87 . The reactions involved an exclusive 1,2-aryl migration along with a metal-free oxidative $\mathrm{C}-\mathrm{C}$ bond formation, mediated by PIFA in the presence of a Lewis acid (Figure 31). ${ }^{65}$

In 2001, Arisawa et a ${ }^{66}$ reported a PIFA-mediated direct intramolecular cyclization of $\alpha$-(aryl)alkyl- $\beta$-dicarbonyl compounds 89 leading to the spirobenzannulated products 90. Both meta- and para-substituted phenol ether derivatives containing cyclic or acyclic 1,3-dicarbonyl moieties on the side chain underwent the annulation in a facile manner (Figure 32).

In 1990, Kikugawa and Kawase ${ }^{67}$ reported an intramolecular oxidative $\mathrm{C}\left(\mathrm{sp}^{2}\right)-\mathrm{N}$ bond formation in substrates $\mathbf{9 1}$, which contained a methoxyamide side chain on the aromatic ring, to give the $N$-aryl- $N$-methoxyamides 92 (Figure 33) via a nitrenium ion intermediate. This oxidative amidation protocol was later applied in many explorations of novel means to construct heterocyclic framework. ${ }^{68-70}$

Starting from $\mathrm{N}$-methoxybenzamide $\mathbf{9 3}$ and alkyne 94, Misu and Togo ${ }^{71}$ developed a straightforward synthesis of isoquinolones 95 using PIDA generated in situ through an intermolecular organocatalytic annulation (Figure 34).

The indenocarboxamides 96 could be converted to the fused indeno-1,4-diazepinones 97 through intramolecular oxidative $\mathrm{C}-\mathrm{N}$ bond formations mediated by PIFA (Figure 35$).{ }^{72}$ Moreover, various PIFA-promoted intramolecular amidation reactions have been developed for the formation of five-, six-, and seven-membered heterocycles. ${ }^{72-75}$

In 2014, Zhao and Du described a PIDA-mediated oxidative coupling of the two aryl groups in either 2-acylamino$N$-phenylbenzamides 98 or 2-hydroxy- $N$-phenylbenzamides 

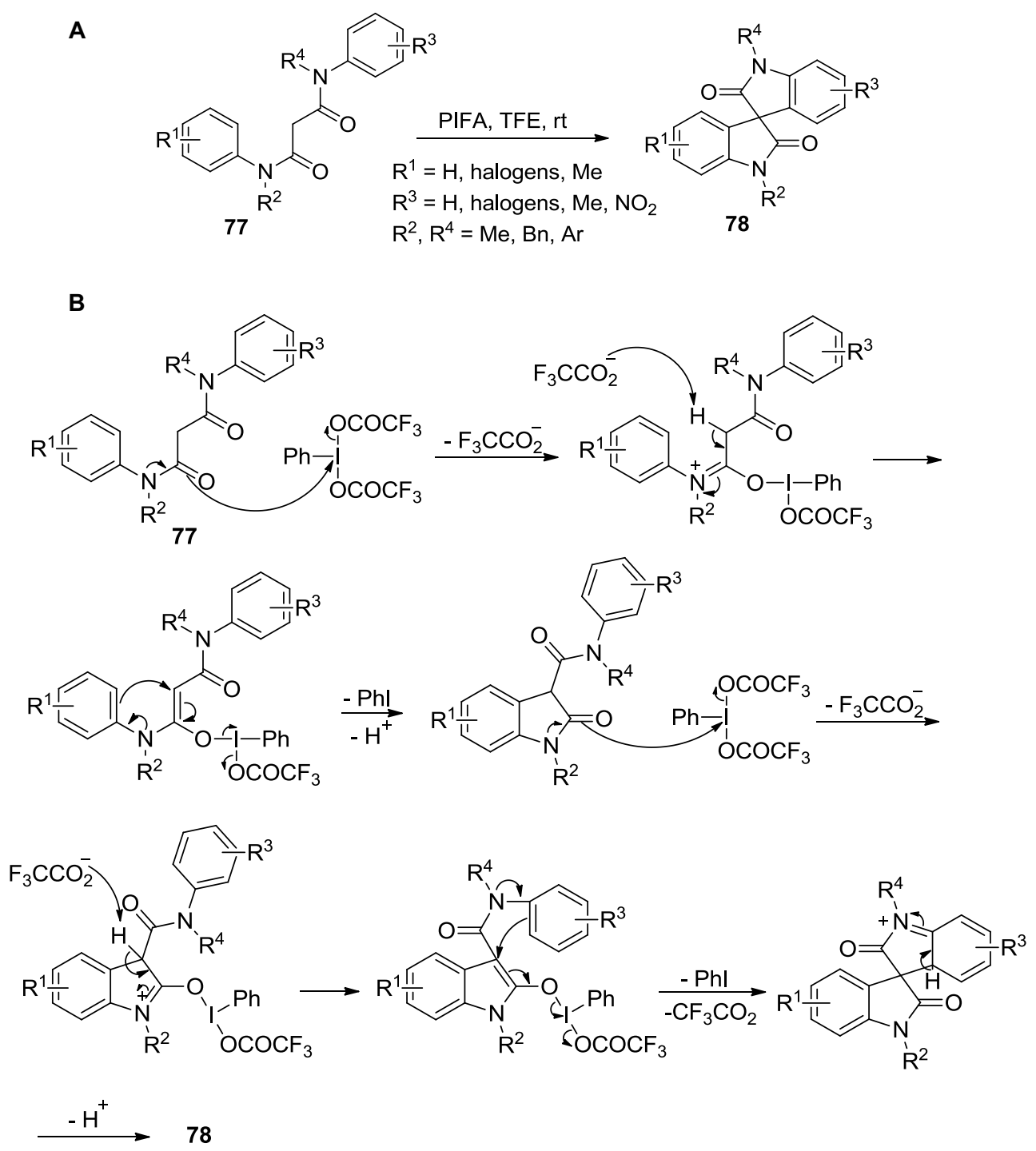

Figure 27 (A) Metal-free synthesis of spirooxindoles via PIFA-mediated cascade oxidation. (B) Proposed mechanism.

Abbreviations: PIFA, phenyliodine bis(trifluoroacetate); rt, room temperature; TFE, 2,2,2-Trifluoroethanol.

100 to afford the dibenzodihydro-1,3-diazepin-2-ones 99 and dibenzo[ $\left[d_{f} f[1,3]\right.$ oxazepin-6(7H)-ones 101, respectively (Figure 36). The reaction sequence involves an oxidative $\mathrm{C}\left(\mathrm{sp}^{2}\right)-\mathrm{C}\left(\mathrm{sp}^{2}\right)$ aryl-aryl bond formation, $\mathrm{C}\left(\mathrm{sp}^{2}\right)-\mathrm{C} / \mathrm{O}$ bond cleavage, and an intramolecular lactamization/lactonization. The unique feature of this conversion is the concomitant insertion of the ortho-substituted $N$ or $O$ atom into the tether, realized for the first time. ${ }^{76}$

A variety of systems involving PIDA/PIFA have been developed to realize functionalization of heterocyclic compounds. Some representative examples are discussed later.

\section{lodination}

By using a combination of PIFA and $\mathrm{I}_{2}$, Benhida et a $\mathrm{l}^{77}$ developed an iodination method suitable for electron-deficient heterocyclic compounds including substituted indoles $\mathbf{1 0 2}$ (Figure 37) and coumarins. Moreover, the methodologies offered reaction conditions mild enough to ensure the survival of sensitive protecting group such as acetyl and tert-butyldimethylsilyl. The methods were also applied to the iodination of substituted pyrazoles in providing the corresponding 4-iodopyrazole derivatives. ${ }^{78}$

Likewise, PIFA-mediated direct cyanations of various heterocyclic compounds including pyrroles, thiophenes, and indoles were realized using trimethylsilyl cyanide as a source of $\mathrm{CN}^{79}$ For example, cyanation of $N$-tosylpyrroles 104 at the $\mathrm{C} 2$ position was achieved by using trimethylsilyl cyanide along with PIFA with moderate-to-excellent selectivity (Figure 38).

Bifunctionalization of glycals 106, including homogeneous azidization and selenylation, has been realized by 
A

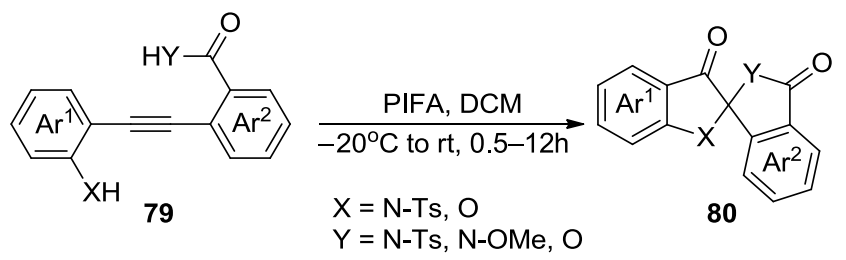

B

\section{Path a}

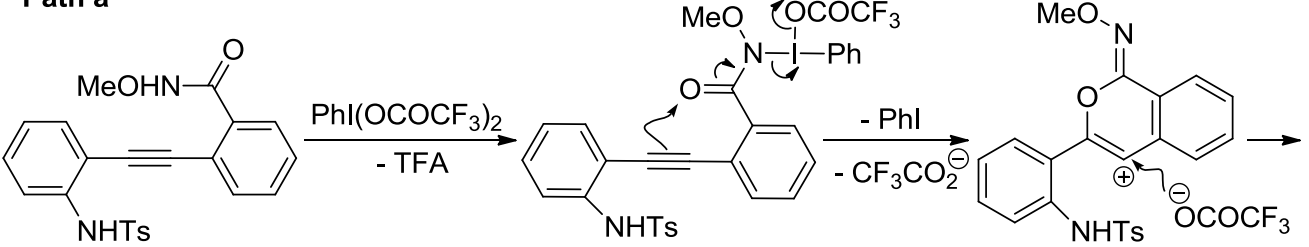
79<smiles>CO/N=c1\oc(-c2ccccc2N)c(OC(F)(F)F)c2ccccc12</smiles>

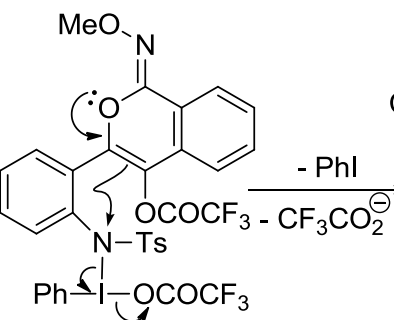

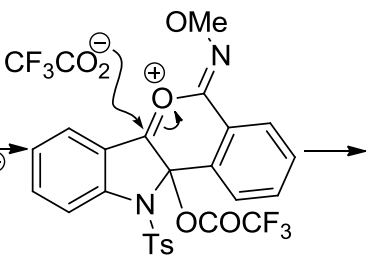

not isolated

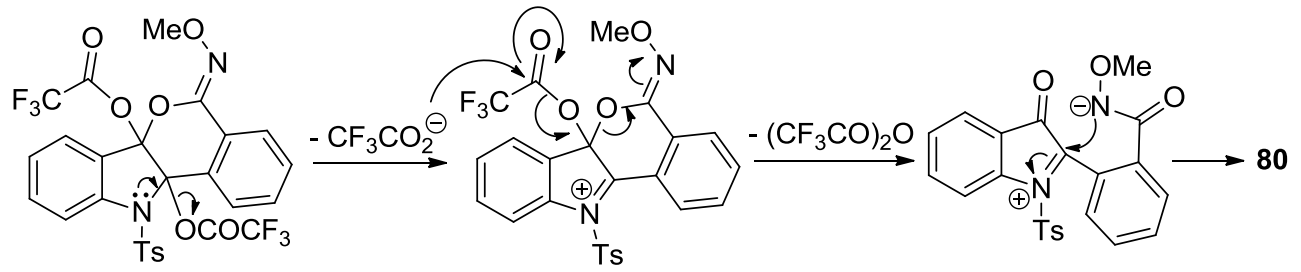

Path b

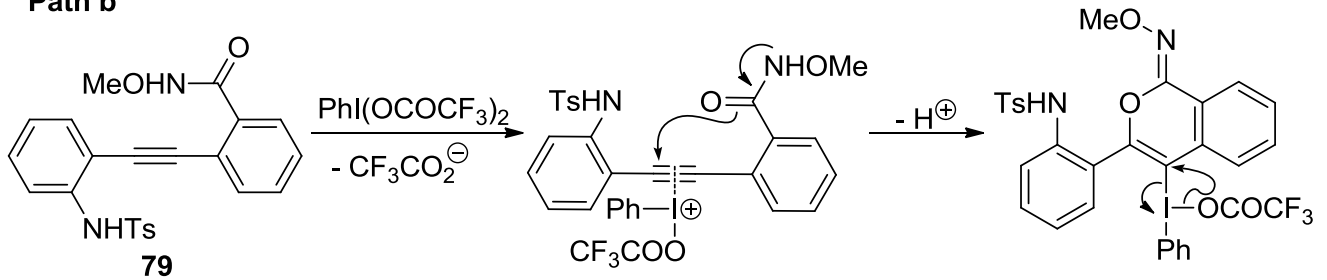

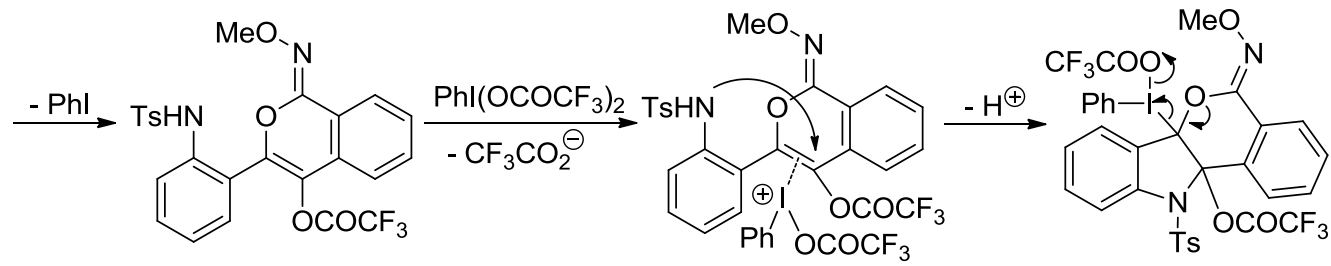

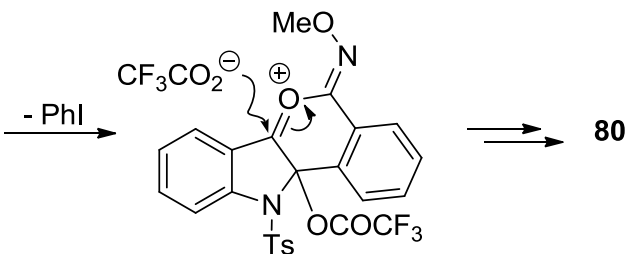

Figure 28 (A) PIFA-mediated conversion of internal alkynes to spiro heterocycles via cascade annulation. (B) Proposed mechanism. Abbreviations: PIFA, phenyliodine bis(trifluoroacetate); rt, room temperature; h, hours; DCM, dichloromethane. 
A<smiles>O=S(=O)(Nc1ccccc1/C=C/c1ccccc1OS(=O)(=O)Oc1ccccc1)Oc1ccccc1</smiles>

81

82

B

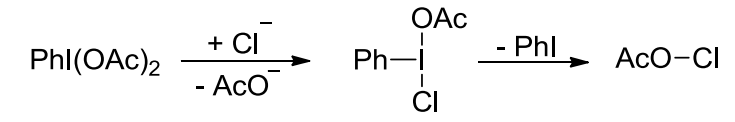<smiles>[R]Nc1ccccc1/C=C/c1ccccc1N[R]</smiles>

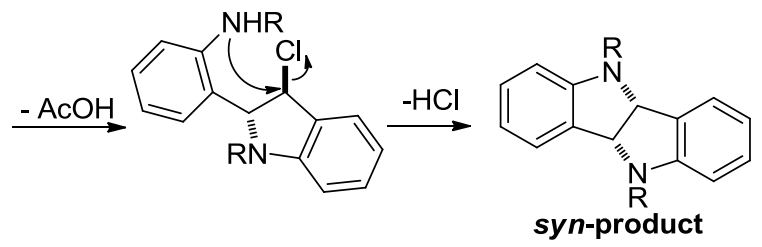

Figure 29 (A) PIDA-mediated synthesis of bisindolines via cascade intramolecular oxidative deamination. (B) Proposed mechanism.

Abbreviations: PIDA, phenyliodine diacetate; rt, room temperature; $h$, hours DMF, N,N-dimethylformamide.<smiles>COc1ccc(C(=O)N(C)c2ccc(OC)c(OC)c2)cc1OC</smiles><smiles>COc1cccc(NCc2ccc(OC)c(OC)c2)c1</smiles>

Figure 30 PIFA-mediated synthesis of benzo[c]phenanthridine and phenanthridinone. Abbreviation: PIFA, phenyliodine bis(trifluoroacetate); DCM, dichloromethane.

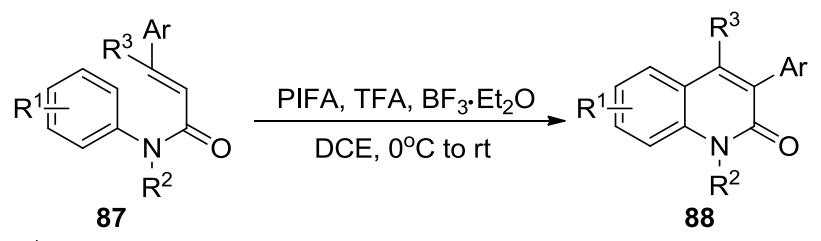

$\mathrm{R}^{1}=\mathrm{H}, \mathrm{Me}$, OMe, $\mathrm{F}, \mathrm{Cl}, \mathrm{Br}, \mathrm{CF}_{3}, \mathrm{CO}_{2} \mathrm{Me}$ $\mathrm{R}^{2}=\mathrm{Me}, \mathrm{Bn}, \mathrm{Pr}$, cyclopropylmethyl; $\mathrm{R}^{3}=\mathrm{H}, \mathrm{Ar} \quad 30 \%-90 \%$ yields

Figure 3I PIFA-mediated synthesis of 3-arylquinolin-2-ones from $\mathrm{N}$-methyl- $\mathrm{N}$ phenylcinnamamides through oxidative $\mathrm{C}-\mathrm{C}$ bond formation/I,2-aryl migration. Abbreviations: PIFA, phenyliodine bis(trifluoroacetate); rt, room temperature; TFA, trifluoroacetic acid; DCE, I,2-dichloroethane.

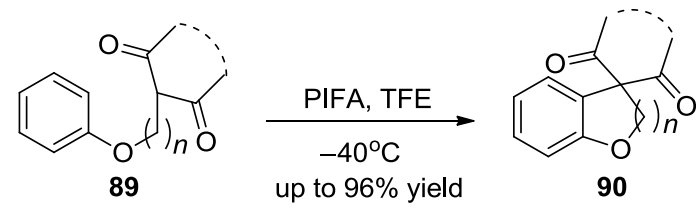

$\mathrm{n}=1$ or 2

Figure 32 PIFA-mediated direct intramolecular cyclization of $\alpha$-(aryl)alkyl- $\beta$-dicarbonyl compounds.

Abbreviations: PIFA, phenyliodine bis(trifluoroacetate); TFE, 2,2,2-Trifluoroethanol.

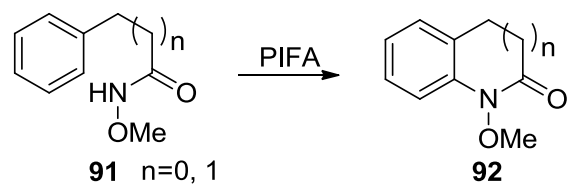

Figure 33 PIFA-mediated synthesis of $\mathrm{N}$-aryl- $\mathrm{N}$-methoxyamides via an intramolecular oxidative $\mathrm{C}-\mathrm{N}$ bond formation.

Abbreviation: PIFA, phenyliodine bis(trifluoroacetate).

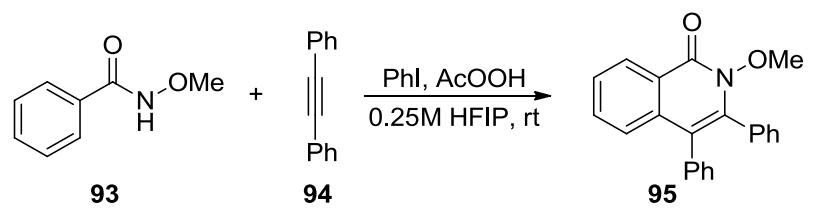

Figure 34 Synthesis of isoquinolones from $\mathrm{N}$-methoxybenzamide and diphenyl acetylene mediated by PIDA generated in situ.

Abbreviations: PIDA, phenyliodine diacetate; $r t$, room temperature.

Mironov et $\mathrm{al}^{80}$ through the reaction of glycals with PIDA in the presence of TMSN 3 and $\mathrm{Ph}_{2} \mathrm{Se}_{2}$ (Figure 39).

\section{[Hydroxy-(organosulfonyloxy)iodo]arenes}

Recently, Kawai et $\mathrm{al}^{81}$ described a new method for the synthesis of biologically significant trifluoromethyl2-isoxazoline $N$-oxides 111. This conversion is realized through the intramolecular oxidative $\mathrm{N}-\mathrm{O}$ coupling in $\beta$-trifluoromethyl- $\beta$-hydroxy ketoximes 109, generated from trifluoromethyl- $\beta$-keto alcohols $\mathbf{1 0 8}$, and mediated by [hydroxy(tosyloxy)iodo]benzene (Figure 40). ${ }^{81}$

Treatment of $2 H$-chromene 112 with [hydroxy(tosyloxy) iodo]benzene in methanol could introduce a methoxyl group at the $\mathrm{C} 4$ position to afford 4-methoxy-2H-chromene 113 (Figure 41). ${ }^{82}$

\section{Benziodoxole-based hypervalent iodine reagents}

During the last decade, studies on the development of the $\lambda^{3}$ iodine benziodoxolone reagents and their applications in facilitating organic transformations have attracted the attention of many synthetic chemists. Some representative examples are presented in this section.

In 2006, Eisenberger et $\mathrm{al}^{83}$ reported the first use of benziodoxole-derived reagents $\mathbf{5 a}$ and $\mathbf{6 b}$ for $\mathrm{CF}_{3}$ transfer. 
A<smiles>O=C(N[Ga])C1=C(NBr)c2ccccc2C1=O</smiles>

96

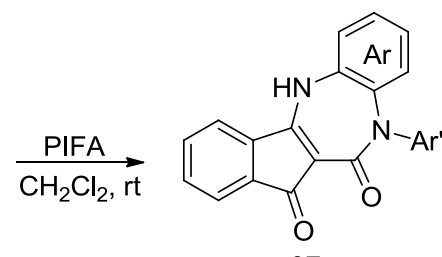

97

B

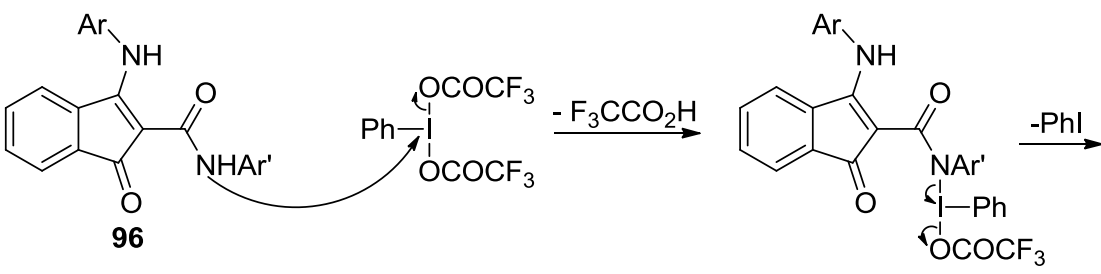

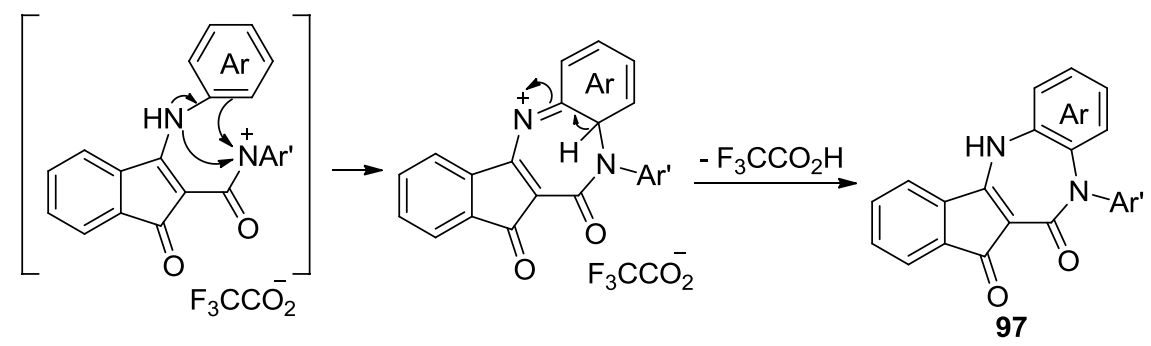

Figure 35 (A) PIFA-mediated synthesis of the fused indeno-I,4-diazepinones. (B) Proposed mechanism. Abbreviations: PIFA, phenyliodine bis(trifluoroacetate); rt, room temperature.

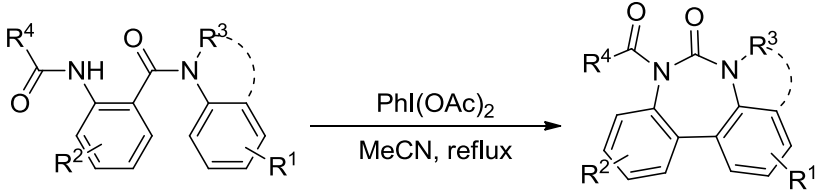

98<smiles>[R]c1cccc(N([R1])C(=O)c2ccccc2O)c1</smiles>

100

\section{$\underset{\mathrm{CH}_{2} \mathrm{Cl}_{2},-35^{\circ} \mathrm{C} \text { or } 0^{\circ} \mathrm{C}}{\longrightarrow}$}

1) $\mathrm{Phl}\left(\mathrm{OCOCF}_{3}\right)_{2}$$$
\mathrm{R}^{2}
$$

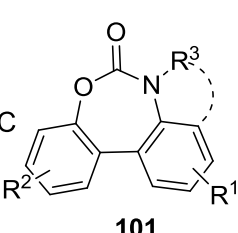

Figure 36 I (III)-mediated formation of dibenzodihydro-1,3-diazepin-2-ones and dibenzo[d,f][1,3]oxazepin-6(7H)-ones.

Abbreviation: $\mathrm{rt}$, room temperature.

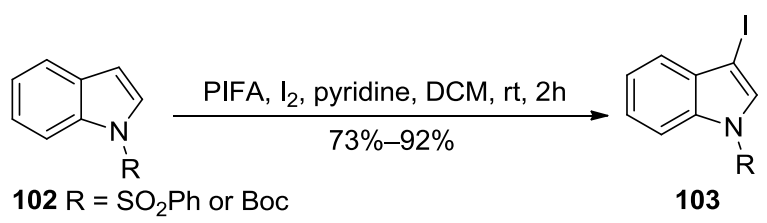

Figure $37 \mathrm{PIFA} / \mathrm{I}_{2}$-mediated iodination of indole derivatives to 3-iodoindoles 103. Abbreviations: PIFA, phenyliodine bis(trifluoroacetate); $r t$, room temperature; $h$, hours; DCM, dichloromethane.

Later on, many practical applications of this class of hypervalent iodine (III) were developed. ${ }^{84,85}$

In 2014, Wang et al ${ }^{86}$ described an intramolecular carbotrifluoromethylation of alkynes $\mathbf{1 1 4}$ by using Togni's reagent in the presence of $\mathrm{Cu}(\mathrm{I})$. A variety of trifluoromethylated

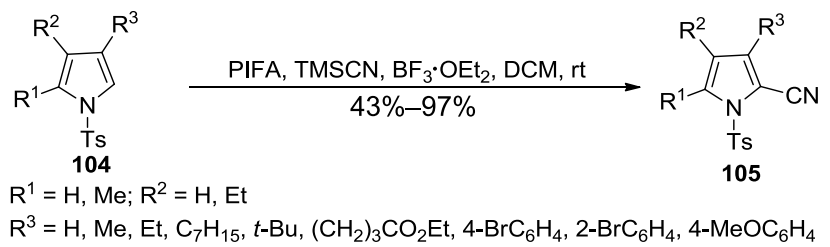

Figure 38 PIFA/TMSCN-mediated selective cyanation of $N$-tosylpyrroles at the $\mathrm{C} 2$ position.

Abbreviations: PIFA, phenyliodine bis(trifluoroacetate); rt, room temperature; TMSCN, trimethylsilyl cyanide; DCM, dichloromethane.

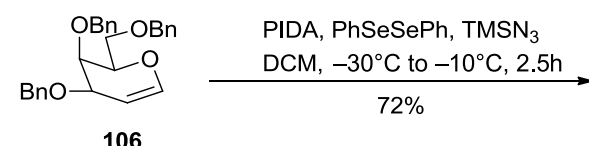

106

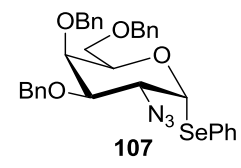

107
Figure 39 PIDA-mediated homogeneous azidization and selenylation of glycals. Abbreviations: PIDA, phenyliodine diacetate; h, hours; DCM, dichloromethane.

heterocycles, such as $2 H$-chromene derivatives $\mathbf{1 1 5}$ and 117, 1,2-dihydroquinoline derivative 116, and the $2 H$-chromene five-membered cyclic product $\mathbf{1 1 8}$, were synthesized with great substituent tolerance and high selectivity (Figure 42).

Due to the multiple reactive sites in indoles, trifluoromethylation of indole derivatives presents a challenge in synthetic chemistry. Shimizu et a ${ }^{87}$ developed a direct C2-selective trifluoromethylation of indole derivatives 119 with 2-trifluoromethyl indole $\mathbf{1 2 0}$ as the product by using Togni's reagent (Figure 43). Later on, a method for the 


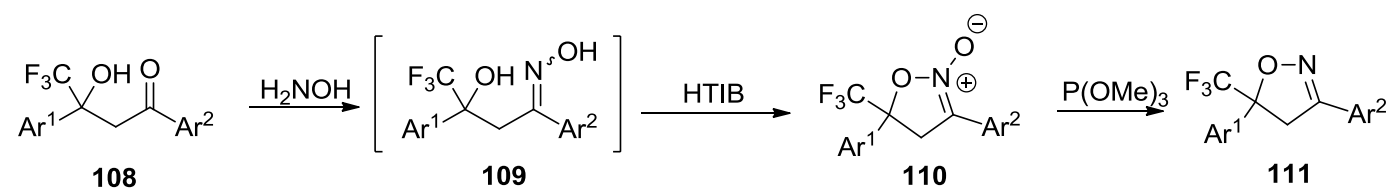

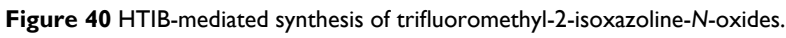
Abbreviation: HTIB, [hydroxy(tosyloxy)iodo]benzene.

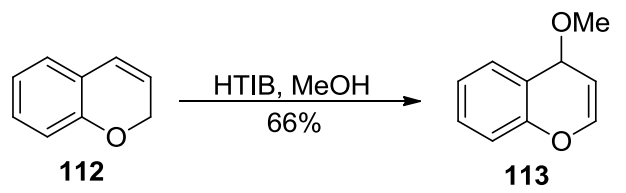

Figure 4I HTIB-mediated synthesis of 4-methoxy-2H-chromene. Abbreviation: HTIB, [hydroxy(tosyloxy)iodo]benzene.

trifluoromethylation of indole compounds to afford the fused tricyclic indoles was established. ${ }^{88}$

In 2014, Zhang and Studer ${ }^{89}$ reported a method for the synthesis of the biologically important 1-trifluoromethylated isoquinolines 122. This transformation starts from the $\beta$-aryl- $\alpha$-isocyano-acrylates $\mathbf{1 2 1}$ and uses Togni's reagent as the $\mathrm{CF}_{3}$ radical precursor to afford the products in moderateto-excellent yield, in the absence of any transition metal (Figure 44).

Recently, by using Togni's reagent and a simple catalyst $\mathrm{CuI}$, Wang et al ${ }^{90}$ reported an elegant method for the aryltrifluoromethylation of $N$-phenylcinnamamides 123 , where a series of $\mathrm{CF}_{3}$-containing 3,4-dihydroquinolin-2(1H)-ones 124 were obtained regioselectively and diastereoselectively (Figure 45). The same conversion from $\mathrm{N}$-arylcinnamamides to $\mathrm{CF}_{3}$-containing dihydroquinolin-2 $(1 H)$-ones was also realized under visible light conditions. ${ }^{91}$

Another widely applied benziodoxole reagent is the [(triisopropylsilyl)ethynyl]benziodoxolone (TIPS-EBX) for its role in introducing alkynyl groups. Although TIPS-EBX had been prepared in $1996,{ }^{92}$ the first significant application was not reported until 2009 by Brand et al. ${ }^{93}$ Direct alkynylation of indole and pyrrole heterocycles $\mathbf{1 2 5}$ was achieved with good functional group tolerance by using TIPS-EBX in the presence of gold as catalyst (Figure 46). ${ }^{94}$

Recently, cobalt(III)-catalyzed C2-alkynylation of indoles 128 using hypervalent iodine-alkyne reagents was reported (Figure 47). ${ }^{95}$ This efficient protocol provided a variety of indole derivatives 129 bearing a C2 alkynyl linker, which can be connected to a series of synthetically useful functional groups such as $-\mathrm{F},-\mathrm{Cl},-\mathrm{Br},-\mathrm{CO}_{2} \mathrm{Me}$, or $-\mathrm{CN}$.

Applying TMS-EBX in the presence of tertiary amines, a metal-free alkynylation of various heterocyclic compounds 130-133 can be realized under mild conditions and affords the corresponding alkynylated heterocyclic compounds
134-137 containing a quaternary carbon in high yields (Figure 48). ${ }^{96}$

In the presence of $\mathrm{CsF}$, cycloaddition between the iodonium ylides 139 and the ortho-silyl aryltriflates 138 afforded a series of benzofurans $\mathbf{1 4 0}$ at room temperature in moderate-to-good yields (Figure 49). ${ }^{97}$

Aryliodonium imides in the presence of metal complexes were reported to efficiently introduce another nitrogen atom into the nitrogen-containing heterocycle compounds. Figure 50 depicts the selective addition of the imido moiety to the $N$ atom of pyridine rings $\mathbf{1 4 1}$ through a Ru-catalyzed $\mathrm{N}-\mathrm{N}$ bond formation. ${ }^{98}$

Arylation of heterocycles with diaryliodonium salts, whether at a carbon or a heteroatom, has drawn much attention from synthetic chemists. One of the most representative examples is the arylation of indole derivatives. In 2006, Deprez et al ${ }^{99}$ developed a method to carry out arylation of indoles 144 at $\mathrm{C} 2$ through a palladium-catalyzed reaction using diaryliodonium salts (Figure 51). This reaction was proven to be compatible with free $\mathrm{N}-\mathrm{H}$ indoles 144, such that no by-product from $N$-arylation was observed.

As arylation using diaryliodonium salts would inevitably generate one equivalent of an iodoarene as a side product, it makes this approach unattractive with regard to atom economy. Recently, a Cu-catalyzed tandem $\mathrm{C}-\mathrm{H} / \mathrm{N}-\mathrm{H}$ arylation of indoles 146 was discovered, which incorporated both aryl groups from the reagent diaryliodonium salts while providing novel indoles 147 (Figure 52). ${ }^{100}$

A significant amount of efforts have been devoted to the arylation of $\mathrm{N}$-containing heterocycles by using diaryliodonium salts and metal catalysts. For example, a Pd-mediated arylation of benzotriazol 148 and a Cu-mediated $N$-arylation of indole 150, cyclohexylamine 152, and the four-membered lactam 154 were realized. Selected examples are presented in Figure 53. ${ }^{101-105}$

In 2013 , Wang et al ${ }^{106}$ realized a $\mathrm{Cu}(\mathrm{OTf})_{2}$-catalyzed regioselective synthesis of polysubstituted quinolines from three components including the diaryliodonium salt 156, the nitrile 157, and the alkyne 158 (Figure 54). It is worth noting that the aryl group of the diaryliodonium serves as a $\mathrm{C} 2$ building block in this reaction. 


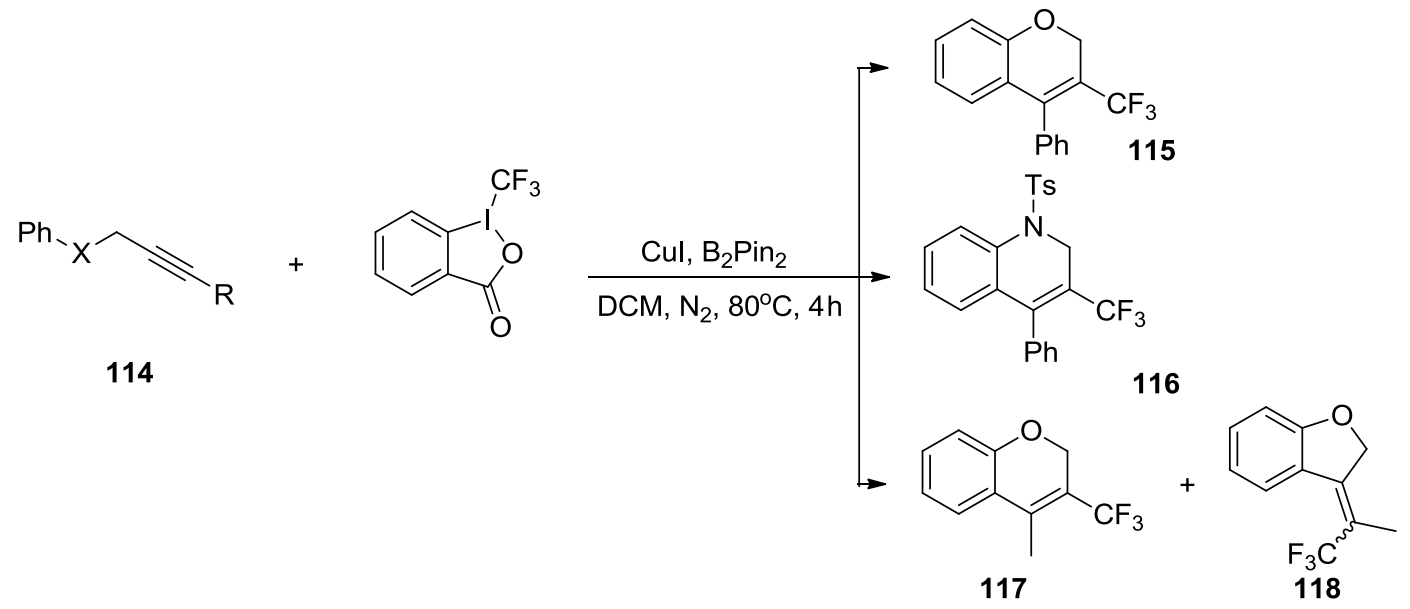

Figure 42 Intramolecular carbotrifluoromethylation of alkynes with Togni's reagent and $\mathrm{Cu}(\mathrm{l})$. Abbreviations: h, hours; DCM, dichloromethane.<smiles>Cc1c[nH]c2ccccc12</smiles>

119<smiles>O=C1OI(C(F)(F)F)c2ccccc21</smiles>

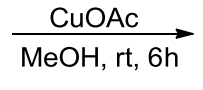

$\mathrm{MeOH}, \mathrm{rt}, 6 \mathrm{~h}$<smiles>Cc1c(C(F)(F)F)[nH]c2ccccc12</smiles>

$120,79 \%$

Figure 43 Trifluoromethylation of indole derivatives with Togni's reagent.

Abbreviations: $r t$, room temperature; $h$, hours.

A<smiles>[CH]=NC(C(C)=O)=C(c1ccccc1)c1ccccc1</smiles><smiles>COC(=O)c1nc(C(F)(F)F)c2ccccc2c1-c1ccccc1</smiles>

B<smiles>COC(=O)c1nc(C(F)(F)F)c2ccccc2c1-c1ccccc1</smiles>

122

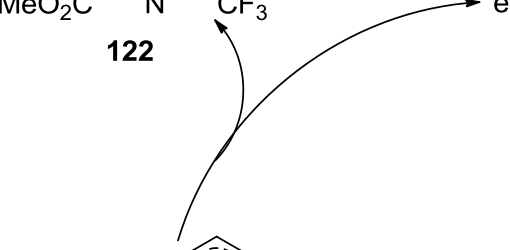<smiles>Cc1cc(C)c2ccccc2c1-c1ccccc1</smiles>

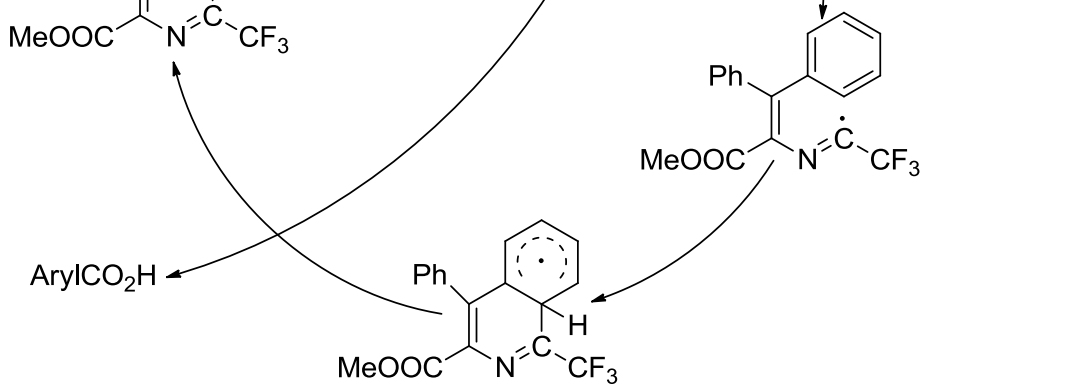
electron injection

Figure 44 (A) Synthesis of biologically important I-trifluoromethylated isoquinolines with Togni's reagent. (B) Proposed mechanism. Abbreviation: h, hours. 


\section{Hypervalent iodine (V) reagents}

Among the iodine (V) compounds, Dess-Martin periodinane (DMP) and 2-iodoxybenzoic acid (IBX) are the two most practical and therefore most widely applied oxidants for their mild characteristics. A large range of syntheses and functionalization of heterocyclic compounds have been achieved in recent years through the applications of iodine $(\mathrm{V})$ reagents.<smiles>[R]C=CC(=O)N([R])c1cc[R1]([H])cc1</smiles>

Figure 45 Aryltrifluoromethylation of $\mathrm{N}$-phenylcinnamamides by using Togni's reagent and copper catalyst.

Abbreviation: $h$, hours.

\section{Dess-Martin periodinane}

DMP was first introduced in 1984. ${ }^{107}$ The most special property of it is its ability to realize selective oxidation of primary and secondary alcohols to their respective aldehydes and ketones. ${ }^{108,109}$ Some applications have been formulated based on this property. For example, when treated with DMP in a hydrocarbon solvent, cleavage of the glycol $\mathrm{C}-\mathrm{C}$ bond in 1,2-diols 160 takes place, leading to the formation of a more complex molecule 162 (Figure 55). ${ }^{110}$

Another example is the synthesis of the 2-substituted benzothiazoles 164 in high yields, which is facilitated by DMP through an intramolecular oxidative cyclization of the thioformanilides 163 in $\mathrm{CH}_{2} \mathrm{Cl}_{2}$. The mild reaction environment plays a key role as the reaction proceeds via a thiol radical intermediate (Figure 56). ${ }^{111}$

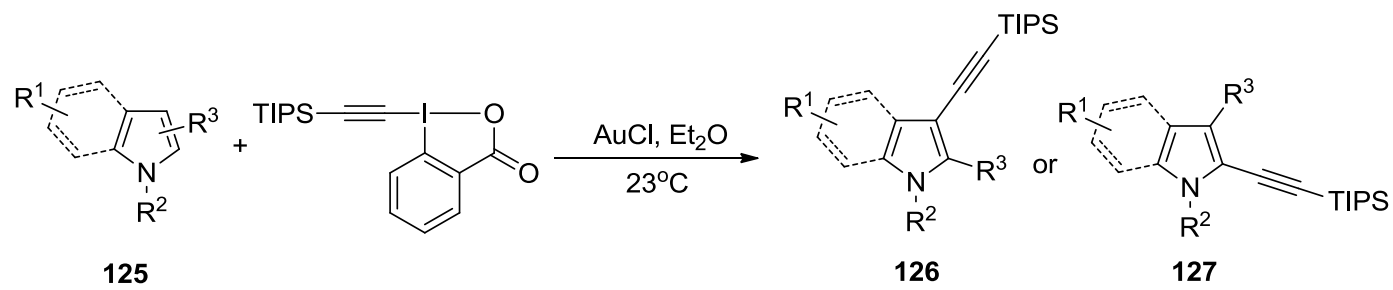

Figure 46 Direct alkynylation of indole and pyrrole heterocycles by using TIPS-EBX.

Abbreviation: TIPS-EBX, [(triisopropylsilyl)ethynyl]benziodoxolone.<smiles>[Y]c1ccccc1-n1ccnc1</smiles>

128

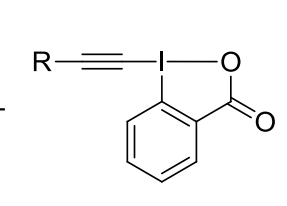

$5 \mathrm{~mol} \%\left[\mathrm{Cp}^{*} \mathrm{Co}\right]$
$\mathrm{AgF}, \mathrm{Mg}\left(\mathrm{OCH}_{3}\right)_{2}$

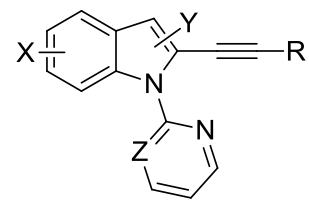

129

$\mathrm{R}=\mathrm{F}, \mathrm{Cl}, \mathrm{Br}, \mathrm{CO}_{2} \mathrm{Me}, \mathrm{CN}$

Figure 47 Selective cobalt(III)-catalyzed alkynylation of indoles using hypervalent iodine-alkyne reagents.

Abbreviations: TFE, 2,2,2-Trifluoroethanol; h, hours; $\mathrm{CP}_{\mathrm{P}}^{*}$, cyclopentadienyl.

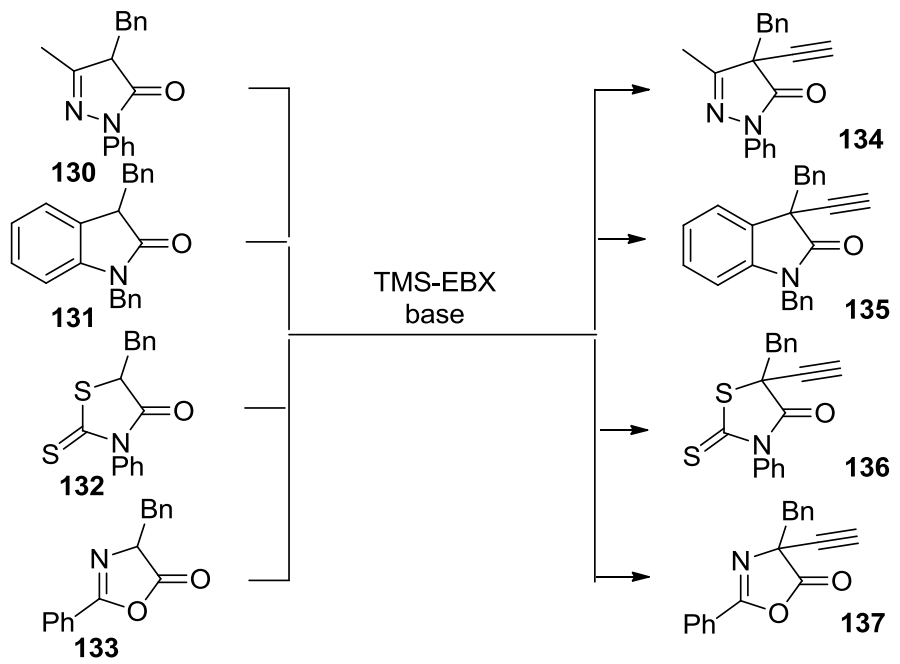

Figure 48 Metal-free alkynylation of various heterocyclic compounds with TMS-EBX. 
A<smiles>[R]C(=O)c1c([R])oc2cc[R1]c3ccc1c32</smiles>

B

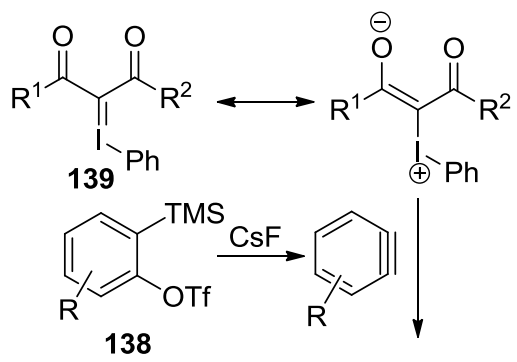

138<smiles>[R]C(=O)C(=I[Tl])C([R])Oc1ccccc1</smiles>

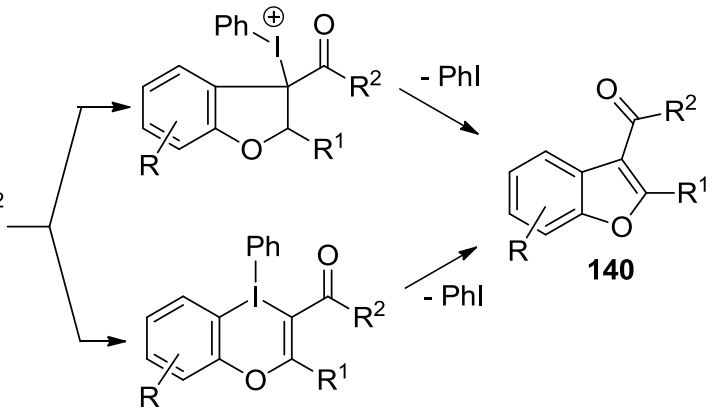

Figure 49 (A) Cycloaddition of ortho-silyl aryltriflates and iodonium ylides. (B) Proposed mechanism. Abbreviation: rt, room temperature.

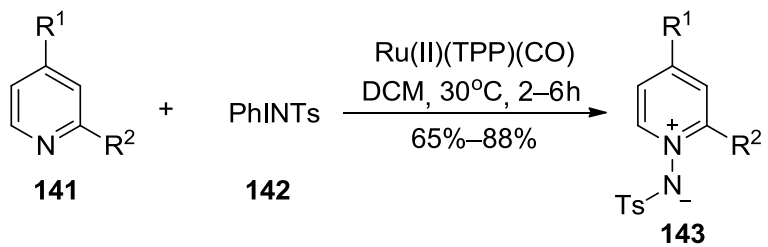

Figure 50 Ru-catalyzed nitrogen atom transfer. Abbreviations: h, hours; DCM, dichloromethane.<smiles>[R]n1ccc2ccccc21</smiles>

$144 \mathrm{R}=\mathrm{H}, \mathrm{Me}$<smiles>[R]n1c(Br)cc2ccc(C[103I])cc21</smiles>

145

Figure 5 I Diaryliodonium salts-mediated arylation of indoles at $\mathrm{C} 2$. Abbreviations: $r t$, room temperature; $h$, hours.

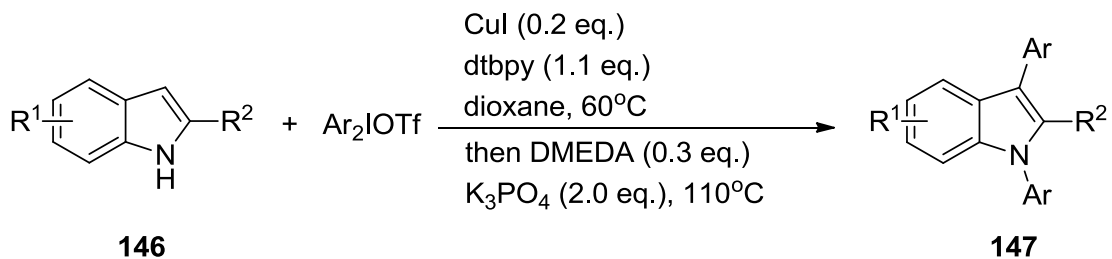

Figure $52 \mathrm{Cu}$-catalyzed tandem $\mathrm{C}-\mathrm{H} / \mathrm{N}-\mathrm{H}$ arylation of indoles with diaryliodonium salts. Abbreviations: eq., equivalent; DMEDA, N,N'-Dimethyl-I,2-ethanediamine. 


\section{lodoxybenzoic acid}

Certain heterocyclic compounds such as isoxazolidines, [1,2]oxazinanes, and 3,5-disubstituted isoxazolines could be synthesized through radical cyclization by using IBX as a single-electron transfer (SET) oxidant. The cyclizations brought about with this protocol could occur in an intramolecular as well as intermolecular manner.

In 2005, Janza and Studer ${ }^{12}$ described the generation of alkoxyamidyl radicals initiated by IBX as an SET oxidant

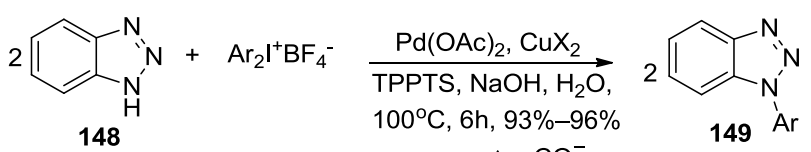

TPPTS $=\mathrm{P}\left(m-\mathrm{NaSO}_{3} \mathrm{C}_{6} \mathrm{H}_{4}\right)_{3}, \mathrm{X}$ , 6h, 93\%-96\%<smiles>c1ccc2[nH]ccc2c1</smiles>

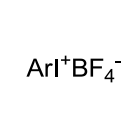

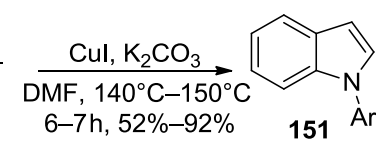

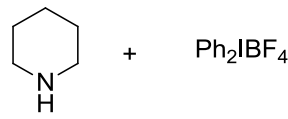

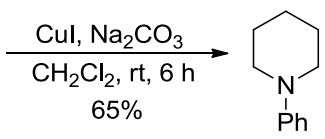

152 $+\mathrm{Ph}_{2} \mathrm{IBF}_{4} \frac{\mathrm{Cu}(\mathrm{acac})_{2}, \mathrm{~K}_{2} \mathrm{CO}_{3}}{\begin{array}{c}\text { toluene, } 50^{\circ} \mathrm{C}, 6 \mathrm{~h} \\ 70 \%\end{array}}$ 154

Figure 53 Arylation of $\mathrm{N}$-containing heterocycles with diaryliodonium salts. Abbreviations: $r t$, room temperature; $h$, hours.

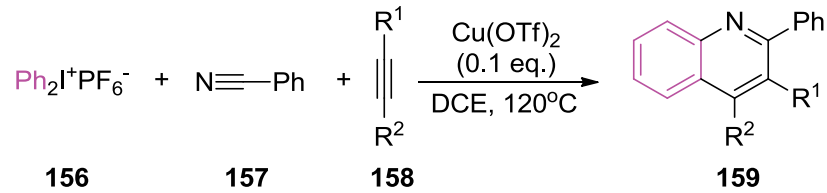

Figure $54 \mathrm{~A} \mathrm{Cu}(\mathrm{OTf})_{2}$-catalyzed, three-component regioselective synthesis of polysubstituted quinolones.

Abbreviations: eq., equivalent; DCE, I,2-dochloroethane. from the acylated alkoxyamines $\mathbf{1 6 5}$. The stereoselective 5-exo and 6-exo reactions with these $N$-heteroatom-centered radicals led to the isoxazolidines $\mathbf{1 6 6}$ a and the [1,2]oxazinanes 166b in good-to-excellent yields (Figure 57).

In 2004, Das et al ${ }^{113}$ reported the preparation of the 3,5-disubstituted isoxazolines $\mathbf{1 6 9}$, achieved via an SET reaction consisting of multiple components of 167 and 168 using IBX as an oxidant (Figure 58). The reaction proceeded through a substituted aldoxime intermediate followed by a 1,3-dipolar addition of an alkene. ${ }^{113}$

Recently, Bredenkamp et al ${ }^{114}$ reported a new example of IBX-promoted direct functionalization of the indoles $\mathbf{1 7 0}$ to the isatins 172. The reagent mixture $171\left(\mathrm{NaI} / \mathrm{IBX}-\mathrm{SO}_{3} \mathrm{~K}\right.$ containing a substituted sulfonyl of IBX) was employed to trigger this oxidative process (Figure 59). ${ }^{114}$

\section{Conclusion}

During the past several decades, hypervalent iodine reagents have been widely used in the syntheses and functionalization of heterocyles. The low production cost has made many of them commercially available, and the low toxicity, being transition metal-free, renders them environmentally friendly. But most importantly, it is their powerful oxidizing properties under mild reaction conditions along with high chemoselectivity that have driven hypervalent iodine chemistry to expand its territory in the field of synthetic chemistry.

\section{Acknowledgments}

We acknowledge the National Natural Science Foundation of China (\#21472136), Tianjin Research Program of Application Foundation and Advanced Technology (\#15JCZDJC32900), and the National Basic Research Project (2014CB932201) for financial support.

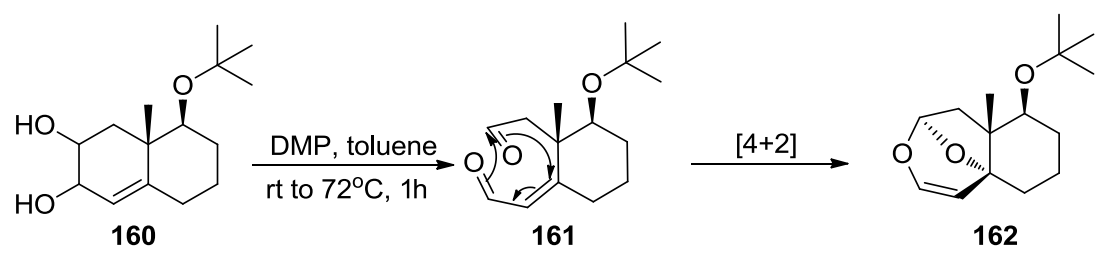

Figure 55 Oxidative cleavage of the glycol $\mathrm{C}-\mathrm{C}$ bond with DMP.

Abbreviations: DMP, Dess-Martin periodinane; $r t$, room temperature; $h$, hours.

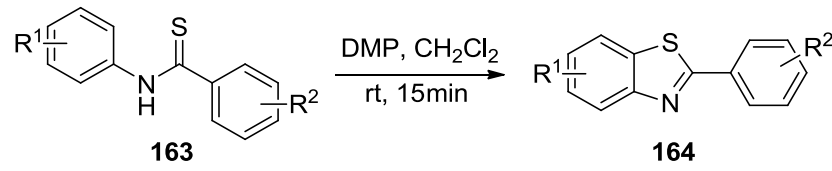

Figure 56 Synthesis of 2-substituted benzothiazoles with DMP.

Abbreviations: DMP, Dess-Martin periodinane; rt, room temperature; min, minutes. 


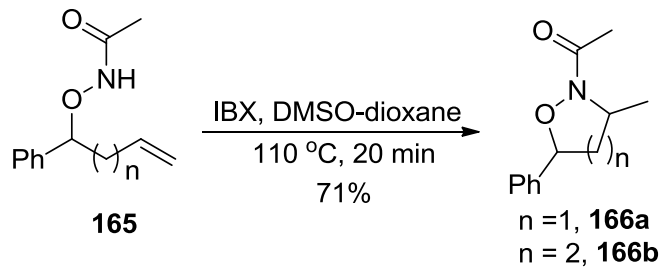

Figure 57 IBX-mediated stereoselective 5-exo and 6-exo formations of isoxazolidines and $[1,2]$ oxazinanes.

Abbreviations: IBX, 2-iodoxybenzoic acid; DMSO, dimethyl sulfoxide; min, minutes.

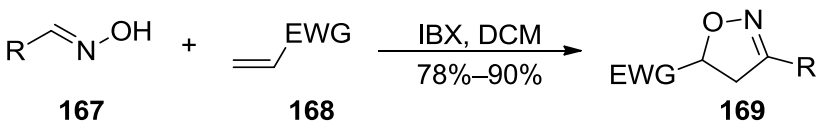

Figure 58 IBX-mediated SET synthesis of isoxazolines involving multiple components.

Abbreviations: IBX, 2-iodoxybenzoic acid; SET, single-electron transfer; DCM, dichloromethane.

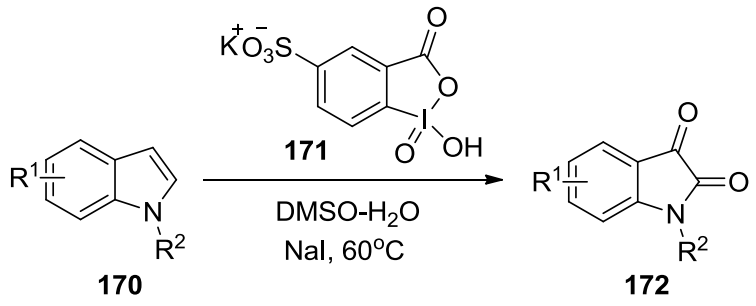

Figure 59 Direct functionalization of indoles to isatins by $\mathrm{Nal} / \mathrm{IBX}-\mathrm{SO}_{3} \mathrm{~K}$. Abbreviation: DMSO, dimethyl sulfoxide.

\section{Author contributions}

All authors contributed toward data analysis, drafting and critically revising the paper and agree to be accountable for all aspects of the work. All authors read and approved the final version of the manuscript.

\section{Disclosure}

The authors report no conflicts of interest in this work.

\section{References}

1. Stang PJ, Zhdankin VV. Organic polyvalent iodine compounds. Chem Rev. 1996;96(3):1123-1178.

2. Moriarty RM, Prakash OM. Synthesis of heterocyclic compounds using organohypervalent iodine reagents. Adv Heterocycl Chem. 1997; 69:1-87.

3. Togo H, Katohgi M. Synthetic uses of organohypervalent iodine compounds through radical pathways. Synlett. 2001;5:0565-0581.

4. Zhdankin VV, Stang PJ. Recent developments in the chemistry of polyvalent iodine compounds. Chem Rev. 2002;102(7):2523-2584.

5. Moreno I, Tellitu I, Herrero MT, SanMartín R, Domínguez E. New perspectives for iodine(III) reagents in (hetero)biaryl coupling reactions. Curr Org Chem. 2002;6:1433-1452.

6. Wirth T. Hypervalent iodine chemistry in synthesis: scope and new directions. Angew Chem Int Ed Engl. 2005;44(24):3656-3665.

7. Zhdankin VV. Benziodoxole-based hypervalent iodine reagents in organic synthesis. Curr Org Synth. 2005;2(1):121-145.

8. Moriarty RM. Organohypervalent iodine: development, applications, and future directions. J Org Chem. 2005;70(8):2893-2903.
9. Richardson RD, Wirth T. Hypervalent iodine goes catalytic. Angew Chem Int Ed. 2006;45(27):4402-4404.

10. Zhdankin VV, Stang PJ. Chemistry of polyvalent iodine. Chem Rev. 2008;108(12):5299-5358.

11. Merritt EA, Olofsson B. Diaryliodonium salts: a journey from obscurity to fame. Angew Chem Int Ed Engl. 2009;48(48):9052-9070.

12. Zhdankin VV. Hypervalent iodine(III) reagents in organic synthesis. ARKIVOC. 2009;i:1-62.

13. Duschek A, Kirsch SF. 2-iodoxybenzoic acid-a simple oxidant with a dazzling array of potential applications. Angew Chem Int Ed. 2011; 50(7):1524-1552.

14. Brand JP, Gonzalez DF, Nicolai S, Waser J. Benziodoxole-based hypervalent iodine reagents for atom-transfer reactions. Chem Commun (Camb). 2011;47(1):102-115.

15. Brown M, Farid U, Wirth T. Hypervalent iodine reagents as powerful electrophiles. Synlett. 2013;24:0424-0431.

16. Parra A, Reboredo S. Chiral hypervalent iodine reagents: synthesis and reactivity. Chemistry. 2013;19(51):17244-17260.

17. Zheng Z, Zhang-Negrerie D, Du Y, Zhao K. The applications of hypervalent iodine(III) reagents in the constructions of heterocyclic compounds through oxidative coupling reactions. Sci China Chem. 2014;57(2):189-214.

18. Narayan R, Manna S, Antonchick AP. Hypervalent iodine(III) in direct carbon-hydrogen bond functionalization. Synlett. 2015;26:1785-1803.

19. Narayan R, Matcha K, Antonchick AP. Metal-free oxidative C-C bond formation through $\mathrm{C}-\mathrm{H}$ bond functionalization. Chemistry. 2015;21(42):14678-14693.

20. Charpentier J, Fruh N, Togni A. Electrophilic trifluoromethylation by use of hypervalent iodine reagents. Chem Rev. 2015;115(2):650-682.

21. Ueno M, Nabana T, Togo $H$. Novel oxidative $\alpha$-tosyloxylation of alcohols with iodosylbenzene and $p$-toluenesulfonic acid and its synthetic use for direct preparation of heteroaromatics. J Org Chem. 2003;68(16):6424-6426.

22. Fan R, Wang H, Ye Y, Gan J. PhIO/Bu $/$ u $_{4}$ I mediated oxidative cyclization of amidoalkylation adducts for the synthesis of $N$-benzoyl aziridines and oxazolines. Tetrahedron Lett. 2010;51:453-456.

23. YeY, Zheng C, Fan R. Solvent-controlled oxidative cyclization for divergent synthesis of highly functionalized oxetanes and cyclopropanes. Org Lett. 2009;11(14):3156-3159.

24. Ye Y, Wang H, Fan R. Stereoselective construction of highly functionalized azetidines via a [2+2]-cycloaddition. Org Lett. 2010;12(12): 2802-2805.

25. Moriarty RM, Vaid RK, Duncan MP. Hypervalent iodine oxidation of amines using iodosobenzene: synthesis of nitriles, ketones and lactams. Tetrahedron Lett. 1988;29(52):6913-6916.

26. Moriarty RM, Rani N, Condeiu C, Duncan MP, Prakash O. Hypervalent iodine oxidation of trimethylsilyl ketene acetals: a convenient route to $\alpha$-methoxylation of esters and lactones. Synth Commun. 1997;27(18):3273-3277.

27. Moriarty RM, Prakash O, Duncan MP, Vaid RK, Rani N. Oxidation of some olefinic compounds using iodosobenzene. J Chem Res Synop. 1996;9:432-433.

28. Francisco CG, Herrera AJ, Suarez E. Intramolecular hydrogen abstraction reaction in carbohydrate chemistry. Synthesis of chiral 2,7-dioxabicyclo[2.2.1]heptane and 6,8-dioxabicyclo[3.2.1]octane ring systems. Tetrahedron Lett. 2000;41:7869-7873.

29. Francisco CG, Freire R, González CC, León EI, Riesco-Fagundo C, Suárez E. Fragmentation of carbohydrate anomeric alkoxy radicals. synthesis of polyhydroxy piperidines and pyrrolidines related to carbohydrates. J Org Chem. 2001;66(5):1861-1866.

30. Francisco CG, Herrera AJ, Suarez E. Intramolecular hydrogen abstraction promoted by $N$-radicals: synthesis of chiral 7-oxa-2-azabicyclo[2.2.1]heptane and 8-oxa-6-azabicyclo[3.2.1] octane ring systems. Tetrahedron. 2000;11:3879-3882.

31. Ochiai M, Inenaga M, Nagao Y. Oxidative decarboxylation of cyclic amino acids and dehydrogenation of cyclic secondary amines with iodosobenzene. Tetrahedron Lett. 1988;29(52):6917-6920. 
32. Caddick S, Motherwell WB, Wilkinson JA. A concise method for the preparation of glycosyl fluorides via displacement reactions of 1-arylthioglycosides with 4-methyl(difluoroiodo)benzene. J Chem Soc Chem Commun. 1991:674-675.

33. Caddick S, Gazzard L, Motherwell WB, Wilkinson JA. Preparation of 1-fluoroglycosides from 1-arylthio and 1-arylselenoglycosides using 4-methyl(difluoroiodo)benzene. Tetrahedron. 1996;52: $149-156$.

34. Inagaki T, Nakamura Y, Sawaguchi M, Yoneda N, Ayuba S, Hara S. Fluorinative ring-expansion of cyclic ethers using $p$-iodotoluene difluoride. Stereoselective synthesis of fluoro cyclic ethers. Tetrahedron Lett. 2003;44:4117-4119.

35. Salamant W, Hulme C. Unique one step, multicomponent $\alpha, \beta, \beta$ oxidations of carbamates with Willgerodt-like hypervalent iodine reagents - an example of triple $\mathrm{C}-\mathrm{H}$ bond activation. Tetrahedron Lett. 2006;47:605-609.

36. Prakash O, Kaur H, Batra H, Rani N, Singh SP, Moriarty RM. $\alpha$-thiocyanation of carbonyl and $\beta$-dicarbonyl compounds using (dichloroiodo)benzene-lead(II) thiocyanate. J Org Chem. 2001;66(6): 2019-2023.

37. Hepples C, Murphy GK. Synthesis of 3,3-dichloro-2-oxindoles from isatin-3-p-tosylhydrazones and (dichloroiodo)benzene. Tetrahedron Lett. 2015;56:4971-4974.

38. Coffey KE, Moreira R, Abbas FZ, Murphy GK. Synthesis of 3,3-dichloroindolin-2-ones from isatin-3-hydrazones and (dichloroiodo)benzene. Org Biomol Chem. 2015;13(3):682-685.

39. He T, Gao WC, Wang WK, Zhang C. Synthesis of oxazolidin-2-ones and imidazolidin-2-ones directly from 1,3-diols or 3-amino alcohols using iodobenzene dichloride and sodium azide. Adv Synth Catal. 2014;356:1113-1118.

40. Li X, Du Y, Liang Z, Li X, Pan Y, Zhao K. Simple conversion of enamines to $2 \mathrm{H}$-azirines and their rearrangements under thermal conditions. Org Lett. 2009;11(12):2643-2646.

41. Zheng Y, Yang C, Zhang-Negrerie D, Du Y, Zhao K. One-pot synthesis of isoxazoles from enaminones: an application of $\mathrm{Fe}(\mathrm{II})$ as the catalyst for ring expansion of $2 \mathrm{H}$-azirine intermediates. Tetrahedron Lett. 2013;54:6157-6160.

42. Zhang PF, Chen ZC. Hypervalent iodine in synthesis 72: a tandem dimerisation-cyclocondensation of enaminones with [bis(trifluoroacetoxy)iodo]benzene: an effective method for the synthesis of highly substituted pyrroles. J Chem Res Synop. 2001:150-152.

43. Wang JY, Liu SP, Yu W. Synthesis of polysubstituted pyrroles via $\mathrm{PhI}(\mathrm{OAc})_{2}$-mediated oxidative coupling of enamine esters and ketones. Synlett. 2009;15:2529-2533.

44. Du YF, Liu RH, Linn G, Zhao K. Synthesis of $N$-substituted indole derivatives via PIFA-mediated intramolecular cyclization. Org Lett. 2006;8(26):5919-5922.

45. Ban X, Pan Y, Lin Y, Wang S, Du Y, Zhao K. Synthesis of carbazolones and 3-acetylindoles via oxidative $\mathrm{C}-\mathrm{N}$ bond formation through PIFA-mediated annulation of 2-aryl enaminones. Org Biomol Chem. 2012;10(18):3606-3609.

46. Yu WQ, Du YF, Zhao K. PIDA-mediated oxidative $\mathrm{C}-\mathrm{C}$ bond formation: novel synthesis of indoles from $N$-aryl enamines. Org Lett. 2009; 11(11):2417-2420.

47. Das B, Srinivas Y, Holla H, Krishnaiah M, Narender R. Hypervalent iodine-mediated efficient synthesis of imidazoles. Chem Lett. 2007;36:1270-1271.

48. Du LH, Wang YG. A rapid and efficient synthesis of benzimidazoles using hypervalent iodine as oxidant. Synthesis. 2007;5:675-678.

49. Kotali A. Synthesis and electron impact mass spectra of 3-substituted 2-acylaminoindazoles. J Heterocycl Chem. 1996;33:605-606.

50. Yu Z, Ma L, Yu W. Phenyliodine bis(trifluoroacetate) mediated intramolecular oxidative coupling of electron-rich $N$-phenyl benzamides. Synlett. 2012;23:1534-1540.

51. Zhao F, Liu X, Qi R, et al. Synthesis of 2-(Trifluoromethyl)oxazoles from $\beta$-monosubstituted enamines via PhI(OCOCF3)2-mediated trifluoroacetoxylation and cyclization. J Org Chem. 2011;76(24):10338-10344.
52. Saito A, Matsumoto A, Hanzawa Y. PIDA-mediated synthesis of oxazoles through oxidative cycloisomerization of propargylamides. Tetrahedron Lett. 2010;51:2247-2250.

53. Prakash O, Batra H, Kaur H, et al. Hypervalent iodine oxidative rearrangement of anthranilamides, salicylamides and some $\beta$-substituted amides: a new and convenient synthesis of 2-benzimidazolones, 2-benzoxazolones and related compounds. Synthesis. 2001;4: 541-543.

54. Downer-Riley NK, Jackson YA. Conversion of thiobenzamides to benzothiazoles via intramolecular cyclization of the aryl radical cation. Tetrahedron. 2008;64:7741-7744.

55. Kumar A, Maurya RA, Ahmad P. Diversity oriented synthesis of benzimidazole and benzoxa/(thia)zole libraries through polymer-supported hypervalent iodine reagent. J Comb Chem. 2009;11(2):198-201.

56. Dohi T, Takenaga N, Goto A, Maruyama A, Kita Y. Direct lactone formation by using hypervalent iodine(III) reagents with $\mathrm{KBr}$ via selective C-H abstraction protocol. Org Lett. 2007;9(16):3129-3132.

57. Wang J, Yuan Y, Xiong R, Zhang-Negrerie D, Du Y, Zhao K. Phenyliodine bis(trifluoroacetate)-mediated oxidative $\mathrm{C}-\mathrm{C}$ bond formation synthesis of 3-hydroxy-2-oxindoles and spirooxindoles from anilides. Org Lett. 2012;14(9):2210-2213.

58. Zhang X, Yang C, Zhang-Negrerie D, Du Y. Hypervalent-iodine-mediated cascade annulation of diarylalkynes forming spiro heterocycles under metal-free conditions. Chemistry. 2015;21(13):5193-5198.

59. Kim H, Cho SH, Chang S. Intramolecular oxidative diamination and aminohydroxylation of olefins under metal-free conditions. Org Lett. 2012;14(6):1424-1427.

60. Kita Y, Gyoten M, Ohtsubo M, Tohma H, Takada T. Non-phenolic oxidative coupling of phenol ether derivatives using phenyliodine(III) bis(trifluoroacetate). Chem Commun. 1996:1481-1482.

61. Taylor SR, Ung AT, Pyne SG, Skelton BW, White AH. Intramolecular versus intermolecular oxidative couplings of ester tethered di-aryl ethers. Tetrahedron. 2007;63:11377-11385.

62. Takada T, Arisawa M, Gyoten M, Hamada R, Tohma H, Kita Y. Oxidative biaryl coupling reaction of phenol ether derivatives using a hypervalent iodine(III) reagent. J Org Chem. 1998;63:7698-7706.

63. Tohma H, Morioka H, Takizawa S, Arisawa M, Kita Y. Efficient oxidative biaryl coupling reaction of phenol ether derivatives using hypervalent iodine(III) reagents. Tetrahedron. 2001;57:345-352.

64. Moreno I, Tellitu I, Etayo J, SanMartin R, Dominguez E. Novel applications of hypervalent iodine: PIFA mediated synthesis of benzo[ $c]$ phenanthiridines and benzo[ $[c]$ phenanthridinones. Tetrahedron. 2001;57:5403-5411.

65. Liu L, Lu H, Wang $\mathrm{H}$, et al. $\mathrm{PhI}\left(\mathrm{OCOCF}_{3}\right)_{2}$-mediated $\mathrm{C}-\mathrm{C}$ bond formation concomitant with a 1,2-aryl shift in a metal-free synthesis of 3-arylquinolin-2-ones. Org Lett. 2013;15(12):2906-2909.

66. Arisawa M, Ramesh NG, Nakajima M, Tohma H, Kita Y. Hypervalent iodine(III)-induced intramolecular cyclization of $\alpha$-(Aryl)alkyl- $\beta$ dicarbonyl compounds: a convenient synthesis of benzannulated and spirobenzannulated compounds. J Org Chem. 2001;66(1):59-65.

67. Kikugawa Y, Kawase M. An electrophilic aromatic substitution by $N$-methoxyamides via hypervalent iodine intermediates. Chem Lett. 1990;4:581-582.

68. Romero AG, Darlington WH, Jacobsen EJ, Mickelson JW. Oxidative cyclization of acyclic ureas with bis(trifluoroacetoxy)iodobenzene to generate $N$-substituted 2-benzimidazolinones. Tetrahedron Lett. 1996;37(14):2361-2364.

69. Herrero MT, Tellitu I, Dominguez E, Moreno I, SanMartín R. A novel and efficient iodine(III)-mediated access to 1,4-benzodiazepin-2-ones. Tetrahedron Lett. 2002;43:8273-8275.

70. Correa A, Tellitu I, Dominguez E, Moreno I, SanMartin R. An efficient PIFA mediated approach to benzo-, naphtho-, and heterocycle-fused pyrrolo[2,1-c][1,4]diazepines. An advantageous access to the antitumor antibiotic DC-81. J Org Chem. 2005;70(6):2256-2264.

71. Misu Y, Togo H. Novel preparation of 2,1-benzothiazine derivatives from sulfonamides with [hydroxy(tosyloxy)iodo] arenes. Org Biomol Chem. 2003;1(8):1342-1346. 
72. Malamidou-Xenikaki E, Spyroudis S, Tsanakopoulou M, HadjipavlouLitina D. A convenient approach to fused indeno-1,4-diazepinones through hypervalent iodine chemistry. J Org Chem. 2009;74(19):7315-7321.

73. Serna S, Tellitu I, Dominguez E, Moreno I, SanMartin R. Iodine(III)mediated aromatic amidation vs olefin amidohydroxylation. The amide $N$-substituent makes the difference. Tetrahedron. 2004;60:6533-6539.

74. Correa A, Tellitu I, Dominguez E, SanMartin R. A metal-free approach to the synthesis of indoline derivatives by a phenyliodine(III) bis(trifluoroacetate)-mediated amidohydroxylation reaction. JOrg Chem. 2006;71(21):8316-8319.

75. Zhu J, Xie H, Chen Z, Li S, Wu Y. Synthesis of $N$-substituted 2-fluoromethylbenzimidazoles via bis(trifluoroacetoxy)iodobenzene-mediated intramolecular cyclization of $N, N$ '-disubstituted fluoroethanimidamides. Synlett. 2009;20:3299-3302.

76. Shang S, Zhang-Negrerie D, Du Y, Zhao K. Intramolecular metal-free oxidative Aryl-Aryl coupling: an unusual hypervalent-iodine-mediated rearrangement of 2-substituted $N$-phenylbenzamides. Angew Chem Int Ed. 2014;53(24):6216-6219.

77. Benhida R, Blanchard P, Fourrey J-L. A mild and effective iodination method using iodine in the presence of bis-(trifluoroacetoxy)iodobenzene. Tetrahedron Lett. 1998;39:6849-6852.

78. Vasilevsky SF, Klyatskaya SV, Tretyakov EV, Elguero J. Ethyl vinyl ether - an agent for protection of the pyrazole NH-fragment. A convenient method for the preparation of $N$-unsubstituted 4-Alkynylpyrazoles. Heterocycles. 2003;60(4):879-886.

79. Dohi T, Morimoto K, Takenaga N, et al. Direct cyanation of heteroaromatic compounds mediated by hypervalent iodine(III) reagents: in situ generation of PhI(III)-CN species and their cyano transfer. J Org Chem. 2007;72(1):109-116.

80. Mironov YV, Sherman AA, Nifantiev NE. Homogeneous azidophenylselenylation of glycals using $\mathrm{TMSN}_{3}-\mathrm{Ph}_{2} \mathrm{Se}_{2}-\mathrm{PhI}(\mathrm{OAc})_{2}$. Tetrahedron Lett. 2004;45:9107-9110.

81. Kawai H, Okusu S, Tokunaga E, Shibata N. Enantioselective synthesis of 5-trifluoromethyl-2-isoxazolines and their $N$-oxides by [Hydroxy(tosyloxy)iodo]benzene-mediated oxidative N-O coupling. Eur J Org Chem. 2013:6506-6509.

82. Ahmad A, Silva LF Jr. Synthesis of chromanes and $4 H$-chromenes: exploring the oxidation of $2 H$-chromenes and dihydro-1-benzoxepines by hypervalent iodine(III). Synthesis. 2012;44(23):3671-3677.

83. Eisenberger P, Gischig S, Togni A. Novel 10-I-3 hypervalent iodinebased compounds for electrophilic trifluoromethylation. Chemistry. 2006;12(9):2579-2586.

84. Stanek K, Koller R, Togni A. Reactivity of a 10-I-3 hypervalent iodine trifluoromethylation reagent with phenols. J Org Chem. 2008;73(19): 7678-7685.

85. Kieltsch I, Eisenberger P, Togni A. Mild electrophilic trifluoromethylation of carbon- and sulfur-centered nucleophiles by a hypervalent iodine(III)- $\mathrm{CF}_{3}$ reagent. Angew Chem Int Ed. 2007;46(5):754.

86. Wang Y, Jiang M, Liu J-T. Copper-catalyzed intramolecular carbotrifluoromethylation of alkynes for the construction of trifluoromethylated heterocycles. Chemistry. 2014;20(47):15315-15319.

87. Shimizu R, Egami H, Nagi T, Chae J, Hamashima Y, Sodeoka M. Direct C2-trifluoromethylation of indole derivatives catalyzed by copper acetate. Tetrahedron Lett. 2010;51:5947-5949.

88. Zhu H, Liu H, Feng X, et al. Copper(I)-promoted trifluoromethylation of indole derivatives with concomitant $\mathrm{C}-\mathrm{C}$ bond formation to access fused tricyclic indoles. Tetrahedron Lett. 2015;56:1703-1705.

89. Zhang B, Studer A. 1-Trifluoromethylated isoquinolines via radical trifluoromethylation of isonitriles. Org Biomol Chem. 2014;12(48): 9895-9898.

90. Wang Q, Han G, Liu Y, Wang Q. Copper-catalyzed aryltrifluoromethylation of $N$-phenylcinnamamides: access to trifluoromethylated 3,4-dihydroquinolin-2(1H)-ones. Adv Synth Catal. 2015;357:2464-2468.

91. Gao F, Yang C, Gao G-L, Zheng L, Xia W. Visible-light induced trifluoromethylation of $\mathrm{N}$-arylcinnamamides for the synthesis of $\mathrm{CF}_{3}$ containing 3,4-disubstituted dihydroquinolinones and 1-azaspiro[4.5] decanes. Org Lett. 2015;17(14):3478-3481.
92. Zhdankin VV, Kuehl CJ, Krasutsky AP, Bolz JT, Simonsen AJ. 1-(Organosulfonyloxy)-3(1H)-1,2-benziodoxoles: preparation and reactions with alkynyltrimethylsilanes. JOrg Chem. 1996;61(19):6547-6551.

93. Brand JP, Charpentier J, Waser J. Direct alkynylation of indole and pyrrole heterocycles. Angew Chem Int Ed Engl. 2009;48(49):9346-9349.

94. Kaschel J, Werz D. Ethynyl benziodoxolone (EBX): installing alkynes the reversed way. Angew Chem Int Ed Engl. 2015;54(31):8876-8878.

95. Zhang Z-Z, Liu B, Wang C-Y, Shi B-F. Cobalt(III)-catalyzed C2-selective C-H alkynylation of indoles. Org Lett. 2015;17(16):4094-4097.

96. Kamlar M, Císařová I, Veselý J. Alkynylation of heterocyclic compounds using hypervalent iodine reagent. Org Biomol Chem. 2015;1 3(10):2884-2889.

97. Huang X-C, Liu Y-L, Liang Y, Pi S-F, Wang F, Li J-H. Cycloaddition of arynes with iodonium ylides: a mild and general route for the synthesis of benzofuran derivatives. Org Lett. 2008;10(8):1525-1528.

98. Jiang Y, Zhou G-C, He G-L, He L, Li J-L, Zheng S-L. Ruthenium(II)porphyrin catalyzed selective $N$-imidation of aromatic nitrogen heterocycles. Synthesis. 2007;10:1459-1464.

99. Deprez NR, Kalyani D, Krause A, Sanford MS. Room temperature palladium-catalyzed 2-arylation of indoles. J Am Chem Soc. 2006;128(15):4972-4973.

100. Modha SG, Greaney MF. Atom-economical transformation of diaryliodonium salts: tandem $\mathrm{C}-\mathrm{H}$ and $\mathrm{N}-\mathrm{H}$ arylation of indoles. $\mathrm{J} \mathrm{Am}$ Chem Soc. 2015;137(4):1416-1419.

101. Beletskaya IP, Davydov DV, Moreno-Manas M. Pd- and Cu-catalyzed selective arylation of benzotriazole by diaryliodonium salts in water. Tetrahedron Lett. 1998;39:5621-5622.

102. Beletskaya IP, Davydov DV, Gorovoy MS. Palladium- and coppercatalyzed selective arylation of 5-aryltetrazoles by diaryliodonium salts. Tetrahedron Lett. 2002;43:6221-6223.

103. Davydov DV, Beletskaya IP, Semenov BB, Smushkevich YI. Regioselective arylation of $N$-tributylstannylated 5 -substituted tetrazoles by diaryliodonium salts in the presence of $\mathrm{Cu}(\mathrm{OAc})_{2}$. Tetrahedron Lett. 2002;43:6217-6219.

104. Kang S-K, Lee S-H, Lee D. Copper-catalyzed $N$-arylation of amines with hypervalent iodonium salts. Synlett. 2000;7:1022-1024.

105. Zhou T, Chen Z-C. Hypervalent iodine in synthesis 85: an efficient method for the synthesis of $N$-arylbenzimidazoles by the coppercatalyzed $N$-arylation of benzimidazole with diaryliodonium salts. Heteroat Chem. 2002;13(7):617-619.

106. Wang Y, Chen C, Peng J, Li M. Copper(II)-catalyzed three-component cascade annulation of diaryliodoniums, nitriles, and alkynes: a regioselective synthesis of multiply substituted quinolines. Angew Chem Int Ed Engl. 2013;52(20):5323-5327.

107. Dess DB, Martin JC. Readily accessible 12-I-5 oxidant for the conversion of primary and secondary alcohols to aldehydes and ketones. J Org Chem. 1983;48:4156-4158.

108. Ladziata U, Zhdankin VV. Hypervalent iodine(V) reagents in organic synthesis. ARKIVOC. 2006;ix:26-58.

109. Wirth T. IBX-new reactions with an old reagent. Angew Chem Int Ed Engl. 2001;40(15):2812-2814.

110. Candela Lena JI, Martín Hernando JI, Rosario Rico Ferreira del M, Altinel E, Arseniyadis S. Tandem glycol cleavage-intramolecular [4 $+2]$ cycloadditions mediated by Dess-Martin periodinane. Synlett. 2001;5:597-600.

111. Bose DS, Idrees M. Hypervalent iodine mediated intramolecular cyclization of thioformanilides: expeditious approach to 2-substituted benzothiazoles. J Org Chem. 2006;71(21):8261-8263.

112. Janza B, Studer A. Stereoselective cyclization reactions of IBX-generated alkoxyamidyl radicals. J Org Chem. 2005;70(17):6991-6994.

113. Das B, Holla H, Mahender G, Banerjee J, Reddy MR. Hypervalent iodine-mediated interaction of aldoximes with activated alkenes including Baylis-Hillman adducts: a new and efficient method for the preparation of nitrile oxides from aldoximes. Tetrahedron Lett. 2004; 45:7347-7350.

114. BredenkampA, Mohr F, Kirsch SF. Synthesis of isatins through direct oxidation of indoles with IBX-SO K/NaI. Synthesis. 2015;47:1937-1943. 
Reports in Organic Chemistry is an international, peer-reviewed, open access journal publishing original research, reports, reviews and commentaries on all areas of organic chemistry. The manuscript management system is completely online and includes a very quick and fair peer-review system, which is all easy to use.

Submit your manuscript here: https://www.dovepress.com/reports-in-organic-chemistry-journal 